\title{
Physiology of Hyperuricemia and Urate-Lowering Treatments
}

\author{
Caroline L. Benn ${ }^{1 *}$, Pinky Dua ${ }^{1}$, Rachel Gurrell ${ }^{1}$, Peter Loudon ${ }^{1}$, Andrew Pike ${ }^{2}$, \\ R. Ian Storer ${ }^{3}$ and Ciara Vangjeli ${ }^{1+}$
}

${ }^{1}$ Pfizer Ltd., Cambridge, United Kingdom, ${ }^{2}$ DMPK, Oncology, IMED Biotech Unit, AstraZeneca, Cambridge, United Kingdom, ${ }^{3}$ MED Biotech Unit, Medicinal Chemistry, Discovery Sciences, AstraZeneca, Cambridge, United Kingdom

\section{OPEN ACCESS}

Edited by:

Ying Ying Leung,

Duke Medical School, National University of Singapore, Singapore

Reviewed by:

Tony Merriman,

University of Otago, New Zealand Anabela Barcelos,

Centro Hospitalar Baixo Vouga,

Portugal

Marcos Edgar Fernández Cuadros, Hospital Universitario Santa Cristina,

Spain

*Correspondence:

Caroline L. Benn

clbenn@gmail.com;

caroline.benn@astx.com

${ }^{\dagger}$ Present Address:

Caroline L. Benn,

CNS biology, Astex Therapeutics,

Cambridge, United Kingdom

Ciara Vangjeli,

Genomics plc, Oxford, United Kingdom

Specialty section:

This article was submitted to Rheumatology,

a section of the journal

Frontiers in Medicine

Received: 12 March 2018 Accepted: 08 May 2018 Published: 31 May 2018

Citation:

Benn CL, Dua P, Gurrell R, Loudon P,

Pike A, Storer Rl and Vangjeli C (2018)

Physiology of Hyperuricemia and

Urate-Lowering Treatments.

Front. Med. 5:160.

doi: 10.3389/fmed.2018.00160
Gout is the most common form of inflammatory arthritis and is a multifactorial disease typically characterized by hyperuricemia and monosodium urate crystal deposition predominantly in, but not limited to, the joints and the urinary tract. The prevalence of gout and hyperuricemia has increased in developed countries over the past two decades and research into the area has become progressively more active. We review the current field of knowledge with emphasis on active areas of hyperuricemia research including the underlying physiology, genetics and epidemiology, with a focus on studies which suggest association of hyperuricemia with common comorbidities including cardiovascular disease, renal insufficiency, metabolic syndrome and diabetes. Finally, we discuss current therapies and emerging drug discovery efforts aimed at delivering an optimized clinical treatment strategy.

Keywords: URAT1, xanthine oxidase, crystal deposition, uric acid, kidney disease, hypertension, diabetes

\section{INTRODUCTION}

Hyperuricemia is a condition characterized by abnormally elevated levels of serum urate (sUA), while gout, the most common form of inflammatory arthritis, arises from the subsequent deposition of urate crystals when concentrations become saturated. Gout has been defined as "a progressive metabolic disease characterized by symptomatic hyperuricemia and deposition of monosodium urate (MSU) crystals in joints and soft tissues due to an imbalance in uric acid uptake, synthesis or excretion" (cited in (1)). The initial clinical sign of an acute gout attack is severe disabling pain, usually involving a single joint, which typically spontaneously resolves over a period of a few days to weeks without intervention, although treatment with anti-inflammatory drugs such as colchicine, NSAIDs (non-steroidal anti-inflammatory drugs) and corticoids will generally improve symptoms more rapidly. Upon resolution of an acute attack the patient will enter a symptom-free interval, however flares can recur with increased frequency and duration if the underlying pathology is not addressed. If sUA values remain high, MSU crystal deposits can grow and expand to other sites leading to further inflammation and associated tissue/joint injury. Ultimately a subset of individuals will transition to chronic tophaceous gout which is characterized by nodular urate crystal deposits, recurrent flares and concurrent arthritis, which takes 11.6 years on average to occur from the initial flare (reviewed in (2)).

It is often stated that the prevalence of hyperuricemia and gout has increased in recent years, although there are relatively few longitudinal studies in geographically diverse populations and increasing diagnosis rates may play a significant role. It has been highlighted that the distribution of gout varies significantly across the world which may reflect factors such as ethnicity, diet and socioeconomic factors (3). In the US the National Health and Nutrition Examination 
Survey [NHANES] 2007-2008 suggested estimating prevalence of gout hyperuricemia and gout at approximately 21 and $4 \%$, respectively, an increase of 3.2 and $1.2 \%$ respectively when compared to the prior NHANES-III study conducted from 1988 to $1994(4,5)$. Likewise, a review of data collected in the Australian population suggested an increase in the prevalence of gout from 0.5 to $1.7 \%$ from 1968 to $1995 / 6$ (6). However, this trend is not universal and data collected in Taiwan over a similar time period, 1993-1996 and 2005-2008, to the US study showed a fall in the prevalence of hyperuricemia from 25.3 to $22.0 \%$ in men and from 16.7 to $9.7 \%$ in women (7). Some authors have argued that this is related to the epidemic of obesity and associated dietary shift toward foods rich in purines, alcohol consumption and fructose-sweetened drinks $(8,9)$; however, this is still disputed and indeed, the impact of dietary intervention may be limited with respect to management of sUA (10).

Many epidemiological studies have shown that hyperuricemia and gout are associated with the development of hypertension, cardiovascular disease, chronic kidney disease and diabetes, potentially through crystal-independent modes of action (1116). Interpretation of these studies is confounded by the specific definition of hyperuricemia that is applied, which in turn contributes to the controversy around the notion of urate having a causal role in these conditions (17). However, it is notable that EULAR (European League Against Rheumatism) now recommends that gout could be seen as a red flag for associated cardiovascular risk factors and co-morbidity, and that blood pressure, lipids and glucose be checked and treated if abnormal (18).

In this article, we review the current knowledge of the physiological and genetic factors involved of uric acid handling in humans. Furthermore, we discuss literature data which examine if hyperuricemia may be a factor in certain comorbidities such as hypertension, cardiovascular disease and chronic kidney disease. Finally, we highlight several current and future therapeutic options for the treatment of hyperuricemia and gout.

\section{URIC ACID}

Uric acid is a weak diprotic acid with an aqueous $\mathrm{pK}_{\mathrm{a} 1}$ of 5.4 and $\mathrm{pK}_{\mathrm{a} 2}$ of 9.8 (19) (Figure 1). Consequently, at physiological pH, uric acid is predominantly (98-99\%) found as the deprotonated urate anion. The solubility of uric acid at normal physiological $\mathrm{pH}$ is generally given as $6.8 \mathrm{mg} / \mathrm{dL}$ while the reference ranges for sUA are 3.5 to $7.2 \mathrm{mg} / \mathrm{dL}(210-430 \mu \mathrm{mol} / \mathrm{L})$ and $2.6-6.0$ $\mathrm{mg} / \mathrm{dL}(155-360 \mu \mathrm{mol} / \mathrm{L})$ in males and premenopausal females respectively (20). It is notable that the upper limit of the normal male reference range includes concentrations that exceed the concentration at which uric acid precipitates.

One interesting aspect of urate biology is the observation that the normal range for serum urate concentrations in humans, and some other primates, are significantly above the typical mammalian range of $0.5-2.0 \mathrm{mg} / \mathrm{dL}(30-120 \mu \mathrm{mol} / \mathrm{L})$. The evolutionary drive for acquisition of comparatively high levels of circulating urate remains unclear, although it has been proposed to confer evolutionary advantages as an anti-oxidant, particularly in the context of neurodegenerative diseases such as Parkinson's $(21,22)$. However, clinical data are conflicting and approaches seeking to increase urate levels have not shown a positive impact on disease outcomes $(23,24)$. In contrast, while any potential benefits of high sUA levels remain to be elucidated it has been clearly demonstrated that hyperuricemia, in conjunction with genetic and/or environmental factors, can lead to significant health problems associated with urate crystal deposition.

\section{Sources of Uric Acid}

Uric acid is produced during the metabolism of both endogenous (daily synthesis rates approximate $300-400 \mathrm{mg}$ ) and exogenous (dietary contribution, approximately $300 \mathrm{mg}$ ) purines within a total pool size of $1,200 \mathrm{mg}$ in healthy males (600 $\mathrm{mg}$ in females) on a purine-free diet $(25,26)$. The relationship between diet and sUA is likely to be more complex than simple purine intake, for example beer and sweetened soft drinks (with high fructose corn syrup as a particularly maligned source) have both been shown to have impact on sUA levels independently of their purine content $(9,27,28)$. Indeed, consistent with the notion of a direct relationship between fructose intake and high sUA levels, it has been shown that increased fructokinase activation leads to the rapid generation of uric acid which in turn upregulates fructokinase expression $(29,30)$.

The biosynthesis of uric acid is catalyzed by the enzyme xanthine oxidase (XO, also known as xanthine oxidoreductase or XOR), coded for by the xanthine dehydrogenase gene $X D H$ (31). The enzyme is normally present as an inactive NAD-dependent cytosolic dehydrogenase precursor, which is subsequently subjected to further processing by oxidation or proteolytic modification to form active enzyme. Xanthine oxidase is widely distributed throughout various organs including the liver, gut, lung, kidney, heart, and brain as well as the plasma and is involved in two stages of uric acid generation; conversion of hypoxanthine to xanthine and subsequently xanthine to uric acid (Figure 2).

\section{Uric Acid Clearance}

In most mammalian species uric acid is further metabolized by the enzyme uricase to the more soluble allantoin (Figure 3) which is subsequently excreted in the urine. However, humans and some higher order primates lack a functional uricase enzyme and therefore uric acid is the final breakdown product of the pathway (21). This discrepancy in uric acid handling between species can represent a significant challenge in the preclinical evaluation of urate lowering drugs during drug discovery.

Urate elimination from humans occurs via two main routes; approximately two-thirds being excreted in urine with normal uricosuria levels of $620 \pm 75 \mathrm{mg} / \mathrm{day}$ in adult, while the remainder is thought to be largely excreted via the gastrointestinal tract $(25,26,32,33)$. Hyperuricemia may also be associated with hyperuricosuria (defined as urinary excretion of urate $>800 \mathrm{mg}$ /day in men and $>750 \mathrm{mg} /$ day in women). Urate elimination can be quantified as clearance (normal males: $8.7 \pm 2.5 \mathrm{~mL} / \mathrm{min}$ ) or as fractional excretion of urate (FEUA) which indicates the net urate excretion by the kidney (normal males: $7.25 \pm 2.98 \%$ ). Healthy subjects 
<smiles></smiles>

Uric acid

Urate salts

98-99\% ionised at $\mathrm{pH} 7.4$

FIGURE 1 | Uric acid pKa and formation of urate salts. Structures of uric acid and urate salts including acid dissociation constants.

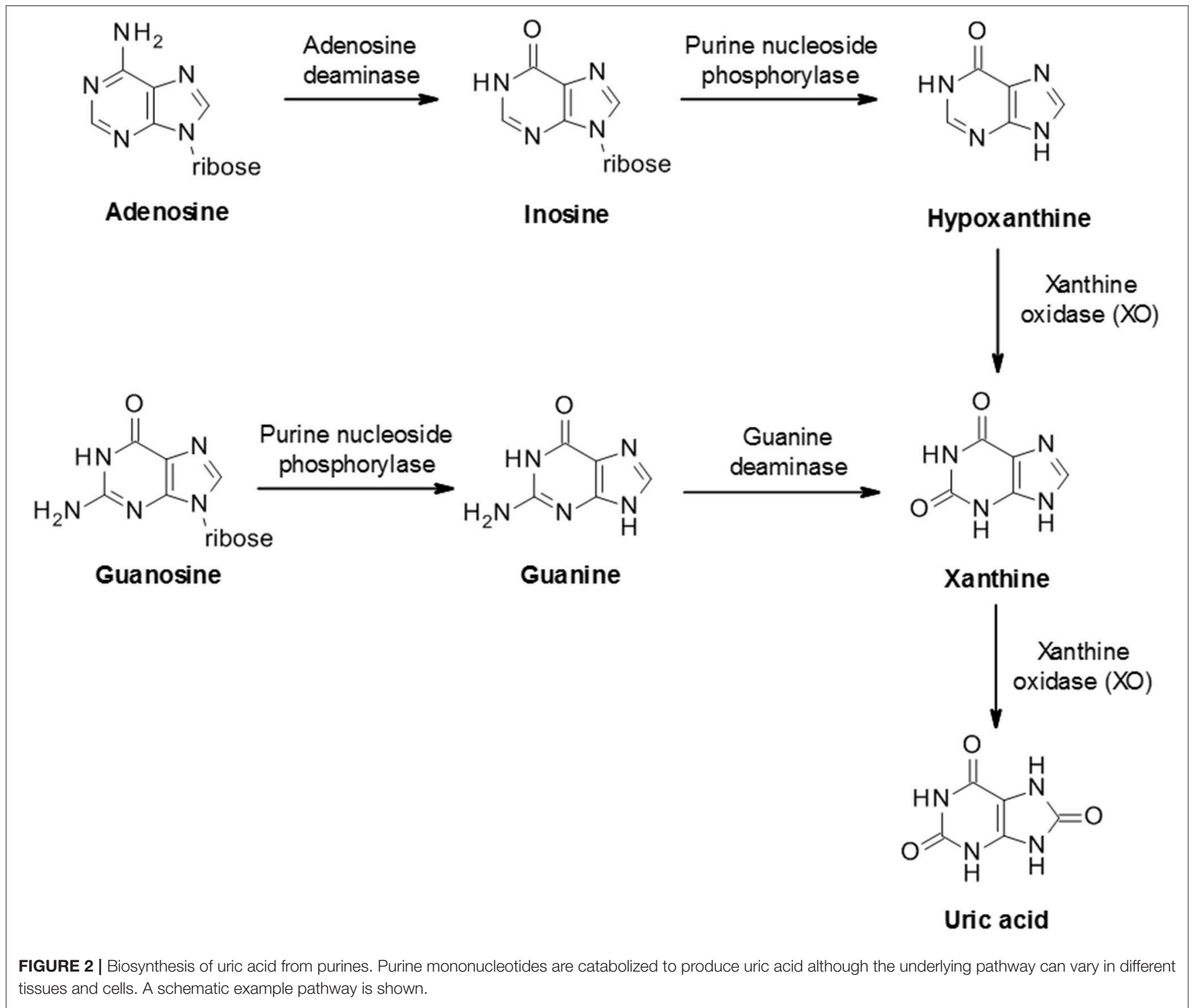

have an average FEUA in the range of $6-8 \%$, whereas gout patients generally have average FEUA of 3-5\% (34-36). These observations are consistent with the notion that decreased renal excretion or low FEUA represents a major contributor to hyperuricemia as opposed to increased generation of uric acid. 


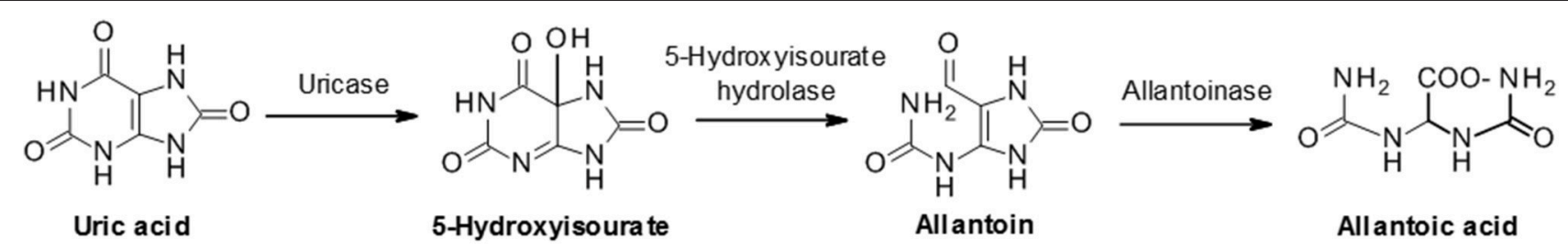

FIGURE 3 | Uric acid metabolism via uricase. In humans and some primates, uric acid is the final product of the purine catabolism pathway. However, most animals further degrade uric acid to allantoic acid via the sequential actions of uricase, 5-hydroxyisourate hydrolase and allantoinase.

Despite the high fraction of renally excreted uric acid, the process is more complex than simple glomerular filtration, with approximately $91-95 \%$ of filtered urate being reabsorbed in the proximal tubule. Reabsorption is a key factor underpinning the comparatively high levels of circulating urate and is primarily mediated by transporters that exchange intracellular anions for urate $(37,38)$. Reabsorption and secretion of urate predominates in the S1 and S2 regions of the proximal tubule although it is not clear whether the secretion happens concomitantly with reabsorption and/or if there is post-reabsorptive secretion within the tubule. Ultimately, around $3-10 \%$ of the filtered urate emerges in the urine. Several transporters playing a role in reabsorption and secretion have been identified (Figure 4).

\section{Urate Reabsorption Transporters URAT1 (SLC22A12)}

The identification of URAT1 (SLC22A12) as the dominant apical (luminal) urate exchanger in the human proximal tubule was a landmark event in the understanding of urate homeostasis (39). URAT1 is a 12-transmembrane domain protein, predominantly expressed on the apical brush border membrane of proximal tubule epithelial cells in the kidneys. URAT1 has been shown to transport urate with a $\mathrm{K}_{\mathrm{m}}$ of $371 \pm 28 \mu \mathrm{M}$ as well as other organic anions such as orotate, salicylate, lactate and nicotinate (39-41). URAT1-mediated urate transport is a tertiary active process dependent on sodium gradients which are initially established via basolateral $\mathrm{Na}^{+} \mathrm{K}^{+}$ATPases which actuate a number of apical $\mathrm{Na}^{+}$coupled organic anion transporters, in turn providing the driving force for urate reabsorption (42, 43).

Clinical genetic studies have confirmed that loss-of-function mutations of URAT1 are associated with FEUA of 40$100 \%$ and extremely low serum urate levels (average levels of $0.93 \mathrm{mg} / \mathrm{dL}$ ) (44) (Table 1). Interestingly, it has been shown that testosterone increases and estradiol decreases URAT1 protein levels in mice and it is interesting to speculate whether this would contribute to the increased hyperuricemia susceptibility in males and post-menopausal women $(89,90)$. Additional genetic susceptibility toward hyperuricemia and gout via PDZK1 association is potentially through its known function of modulating the apical membrane localization of URAT1 (57, 91) (Table 1). While URAT1 appears to be the predominant apical reabsorption transporter, other pathways are inferred given that FEUA is $<100 \%$ even in patients with complete URAT1 loss of function mutations.

URAT1 is now a well-established drug target with a number of primary and secondary uricosurics (drugs capable of increasing FEUA) such as benzbromarone, probenecid and lesinurad, known to derive at least part of their efficacy through this mechanism albeit, in earlier cases, this was not understood when they were developed (92-97). Interestingly, compounds such as pyrazinamide have been shown to trans-stimulate URAT1 activity to impact on vectorial transport of urate $(72,98)$.

\section{GLUT9 (SLC2A9)}

Variants in glucose transporter 9 (GLUT9, also referred to as URATv1), coded for by the SLC2A9 gene, are strongly associated with both hyperuricemia and gout, a finding that has been successfully replicated in multiple studies (59, 99) (Table 1). In addition, individuals with homozygous mutations in GLUT9 present with pronounced hypouricemia and hyperuricosuria with FEUA's of $100 \%$ or greater (indicative of net active urate secretion), response to fructose load, and a propensity for nephrolithiasis and exercise induced renal failure (62, 84, 100-102).

GLUT9 appears to function predominantly as a facilitative urate uniporter with at least some additional capacity for hexose transport $(59,103,104)$. GLUT9-mediated urate transport is voltage dependent with currents recorded at physiological $\mathrm{pH}$, but independent of sodium, chloride and other ions. Consequently, GLUT9 is distinct from other members of the glucose transporter (SLC2) family due to its substrate specificity and sequence identity although it shares common structural features such as 12 transmembrane helices, cytoplasmic termini, and an N-linked glycosylation site. Two isoforms of GLUT9 have been described that differ only by the first 29 residues of the Nterminal domains (104). The short isoform (GLUT9a) appears to be expressed at both apical and basolateral membranes in proximal tubule epithelium cells (and indeed may contribute to the import of urate from the peritubular interstitium and thus facilitate renal urate secretion). The long isoform (GLUT9b) is predominantly expressed on the basolateral membrane and is the only known basolateral efflux transporter for urate.

Interestingly, a positive relationship has been described between glycosuria and uricosuria suggesting that there could be interference between the tubular reabsorption of glucose and the tubular capacity to reabsorb urate (105). Indeed, it has been 


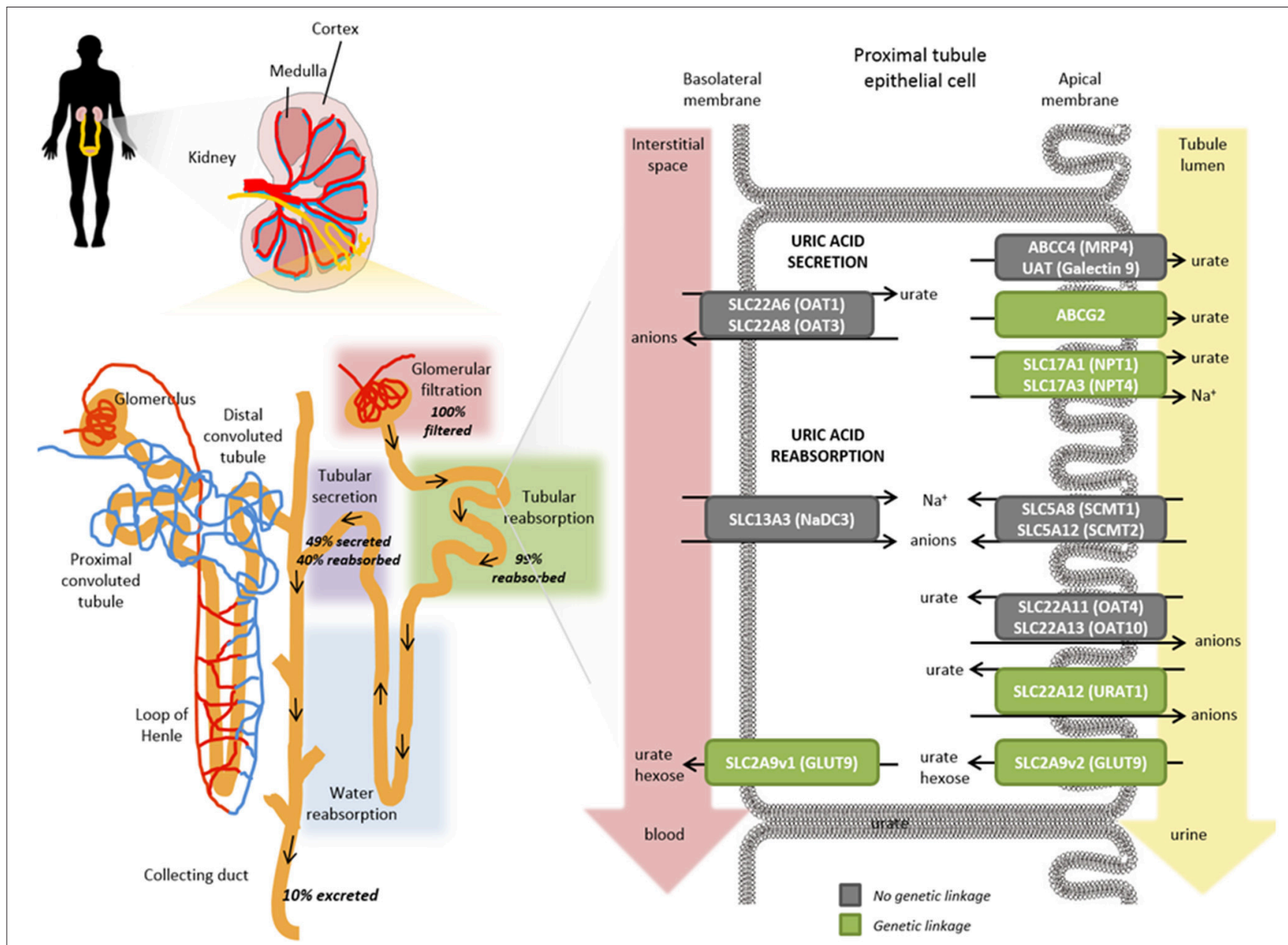

FIGURE 4 | Role of transporters in the renal proximal tubule on urate handling. Within an individual nephron in the kidney (yellow), filtration of water and solutes occurs in the glomerular capsule from the afferent arteriole into the renal tubule (pink shading). Tubular reabsorption (green shading) is predominantly mediated by the proximal convoluted tubule whereas tubular secretion extracts uric acid (and other substances) from peritubular capillaries (purple shading) and secretes them into the tubular fluid for urinary excretion. Urate transporters in renal proximal tubule epithelial cells actively mediate the secretion and reabsorption of urate. The balance between these processes determines the net excretion levels from the kidney. The anion transporters SLC22A6 (OAT1) and SLC22A8 (OAT3) localized on the basolateral membranes transport urate from the interstitial space in the blood depending on the gradients for exchanged anions but have not been shown to exhibit a genetic linkage with hyperuricemia or gout risk (gray box). On the apical membrane, ABCG2, SLC17A1 (NPT1), SLC17A3 (NPT4), ABCC4 (MRP4), UAT (Galectin 9) have all been shown to contribute to the secretory transport of urate into the tubule lumen and leading to urinary excretion; a number of these have been genetically associated with hyperuricemia and gout risk (green boxes). Exchange gradients upstream of urate anion exchange are enabled through the actions of SLC13A3 (NaD3), SLC5A8 (SCMT1), and SLC5A12 (SCMT2). In renal reabsorption, the apical urate-anion exchanger SLC22A12 (URAT1) has been shown to play a predominant role in urate homeostasis and indeed several variants have been identified to be associated with gout and hyperuricemia risk (green box). Additional contributions to urate reabsorption are mediated by SLC22A11 (OAT4) and SLC22A11 (OAT10) (gray boxes, not genetically associated with gout/hyperuricemia risk) and the short isoform of SLC2A9v2 (GLUT9, green box) on the apical membrane. The long isoform of SLC2A9v1 (GLUT9, green box) is the only known transporter to mediate basolateral efflux of urate back into circulation; which is in accordance with its genetic association for gout and hyperuricemia risk in addition to rare mutations associated with hypouricemia.

proposed that SGLT2 inhibitor treatment lowers serum uric acid through alteration of uric acid transport activity in renal tubules. This is consistent with clinical observations with canagliflozin treatment decreasing serum urate in patients with type 2 diabetes (a known co-morbidity of hyperuricemia), including those with baseline hyperuricemia (106-108). Therefore, studies which assess urate lowering therapy (ULT) efficacy should also consider ambient glycemia which could contribute to the uricosuric effect (109).

\section{OAT4 (SLC22A11) and OAT10 (SLC22A13)}

Organic anion transporters 4 (OAT4) and 10 (OAT10) have a range of organic anion substrates and are expressed on the apical membrane of proximal tubule epithelium cells together with URAT1 (SLC22A12) (99). While both transporters have been demonstrated to exhibit low levels of urate transport capabilities, only OAT4 has been associated with hyperuricemia and gout together with inefficient renal secretion $(78,80)$. 
TABLE 1 | Genetic associations with urate levels.

\begin{tabular}{|c|c|c|c|c|c|}
\hline $\begin{array}{l}\text { Genomic } \\
\text { location }\end{array}$ & $\begin{array}{l}\text { Candidate } \\
\text { gene* }^{\star}\end{array}$ & $\begin{array}{l}\text { Protein encoded by } \\
\text { candidate gene }\end{array}$ & Function (if known) provided by RefSeq & $\begin{array}{l}\text { Genetic association with } \\
\text { gout/hyperuricemia }\end{array}$ & References \\
\hline $4 q 22.1$ & ABCG2 & BCRP & $\begin{array}{l}\text { The membrane-associated protein encoded by } \\
\text { this gene is included in the superfamily of } \\
\text { ATP-binding cassette (ABC) transporters which } \\
\text { transport various molecules across extra- and } \\
\text { intra-cellular membranes. ABCG } 2 \text { can function } \\
\text { as a xenobiotic transporter which may play a } \\
\text { major role in multi-drug resistance. It likely } \\
\text { serves as a cellular defense mechanism in } \\
\text { response to mitoxantrone and anthracycline } \\
\text { exposure }\end{array}$ & $\begin{array}{l}\text { Multiple common variant associations } \\
\text { with serum urate levels, renal } \\
\text { under-excretion gout and overall risk } \\
\text { of gout }\end{array}$ & $(45-56)$ \\
\hline $2 q 22.3$ & ACVR2A & $\begin{array}{l}\text { Activin A receptor type } \\
2\end{array}$ & $\begin{array}{l}\text { This gene encodes a transmembrane } \\
\text { serine-threonine kinase receptor that mediates } \\
\text { the functions of activins (members of the } \\
\text { transforming growth factor-beta (TGF-beta) } \\
\text { superfamily). This gene may be associated with } \\
\text { susceptibility to preeclampsia, a } \\
\text { pregnancy-related disease which can result in } \\
\text { maternal and fetal morbidity and mortality }\end{array}$ & $\begin{array}{l}\text { Common variant association with } \\
\text { serum urate levels }\end{array}$ & (50) \\
\hline $10 q 11.2$ & ASAH2 & $\begin{array}{l}\mathrm{N} \text {-acylsphingosine } \\
\text { amidohydrolase } 2\end{array}$ & $\begin{array}{l}\text { Ceramidases (EC 3.5.1.23) such as ASAH2, } \\
\text { catalyze hydrolysis of the N-acyl linkage of } \\
\text { ceramide, a second messenger in a variety of } \\
\text { cellular events, to produce sphingosine. } \\
\text { Sphingosine exerts both mitogenic and } \\
\text { apoptosis-inducing activities, and its } \\
\text { phosphorylated form functions as an intra- and } \\
\text { intercellular second messenger }\end{array}$ & $\begin{array}{l}\text { Common variant association with } \\
\text { serum urate levels }\end{array}$ & (50) \\
\hline $17 q 23.2$ & C17ORF82 & $\begin{array}{l}\text { Chromosome } 17 \text { open } \\
\text { reading frame } 82\end{array}$ & Unknown & $\begin{array}{l}\text { Common variant association with } \\
\text { serum urate levels }\end{array}$ & (50) \\
\hline $2 \mathrm{p} 23.3$ & GCKR & Glucokinase regulator & $\begin{array}{l}\text { The gene product is a regulatory protein that } \\
\text { inhibits glucokinase in liver and pancreatic islet } \\
\text { cells by binding non-covalently to form an } \\
\text { inactive complex with the enzyme. This gene is } \\
\text { considered a susceptibility gene candidate for } \\
\text { a form of maturity-onset diabetes of the young } \\
\text { (MODY) }\end{array}$ & $\begin{array}{l}\text { Common variant association with } \\
\text { serum urate levels }\end{array}$ & (50) \\
\hline $8 q 21.13$ & HNF4G & $\begin{array}{l}\text { Hepatocyte nuclear } \\
\text { factor } 4 \text { gamma }\end{array}$ & $\begin{array}{l}\text { This gene is also known as NR2A2 (nuclear } \\
\text { receptor subfamily 2, group A, member 2). } \\
\text { HNF4 was originally classified as an orphan } \\
\text { receptor that exhibits constitutive } \\
\text { transactivation activity through fatty acid } \\
\text { bindings. Mutations in the HNF4A gene have } \\
\text { been linked to maturity onset diabetes of the } \\
\text { young } 1 \text { (MODY1) }\end{array}$ & $\begin{array}{l}\text { Common variant association with } \\
\text { serum urate levels }\end{array}$ & (50) \\
\hline $15 q 26.3$ & IGF1R & $\begin{array}{l}\text { Insulin like growth } \\
\text { factor } 1 \text { receptor }\end{array}$ & $\begin{array}{l}\text { This receptor binds insulin-like growth factor } \\
\text { with a high affinity. It has tyrosine kinase activity. } \\
\text { Cleavage of the precursor generates alpha and } \\
\text { beta subunits. The insulin-like growth factor I } \\
\text { receptor plays a critical role in transformation } \\
\text { events and is highly overexpressed in most } \\
\text { malignant tissues where it functions as an } \\
\text { anti-apoptotic agent by enhancing cell survival }\end{array}$ & $\begin{array}{l}\text { Common variant association with } \\
\text { serum urate levels }\end{array}$ & (50) \\
\hline $2 q 14.2$ & INHBB & Inhibin beta B subunit & $\begin{array}{l}\text { This gene encodes a member of the TGF-beta } \\
\text { (transforming growth factor-beta) superfamily of }\end{array}$ & $\begin{array}{l}\text { Common variant association with } \\
\text { serum urate levels }\end{array}$ & (50) \\
\hline
\end{tabular}


TABLE 1 | Continued

\begin{tabular}{|c|c|c|c|c|c|}
\hline $\begin{array}{l}\text { Genomic } \\
\text { location }\end{array}$ & $\begin{array}{l}\text { Candidate } \\
\text { gene }^{\star}\end{array}$ & $\begin{array}{l}\text { Protein encoded by } \\
\text { candidate gene }\end{array}$ & Function (if known) provided by RefSeq & $\begin{array}{l}\text { Genetic association with } \\
\text { gout/hyperuricemia }\end{array}$ & References \\
\hline & & & $\begin{array}{l}\text { proteins. The encoded preproprotein is } \\
\text { proteolytically processed to generate a subunit } \\
\text { of the dimeric activin and inhibin protein } \\
\text { complexes. Polymorphisms near this gene are } \\
\text { associated with pre-eclampsia in female } \\
\text { human patients }\end{array}$ & & \\
\hline $11 q 13.1$ & LTBP3 & $\begin{array}{l}\text { Latent transforming } \\
\text { growth factor beta } \\
\text { binding protein } 3\end{array}$ & $\begin{array}{l}\text { The protein encoded by this gene forms a } \\
\text { complex with transforming growth factor beta } \\
\text { (TGF-beta) proteins and may be involved in } \\
\text { their subcellular localization. This protein also } \\
\text { may play a structural role in the extracellular } \\
\text { matrix }\end{array}$ & $\begin{array}{l}\text { Common variant association with } \\
\text { serum urate levels }\end{array}$ & (50) \\
\hline $3 p 21.1$ & MUSTN1 & $\begin{array}{l}\text { Musculoskeletal, } \\
\text { embryonic nuclear } \\
\text { protein } 1\end{array}$ & Unknown & $\begin{array}{l}\text { Common variant association with } \\
\text { serum urate levels }\end{array}$ & (50) \\
\hline $16 q 22.1$ & NFAT5 & $\begin{array}{l}\text { Nuclear factor of } \\
\text { activated T-cells } 5\end{array}$ & $\begin{array}{l}\text { Proteins belonging to this family play a central } \\
\text { role in inducible gene transcription during the } \\
\text { immune response. This protein regulates gene } \\
\text { expression induced by osmotic stress in } \\
\text { mammalian cells }\end{array}$ & $\begin{array}{l}\text { Common variant association with } \\
\text { serum urate levels }\end{array}$ & (50) \\
\hline $15 q 24.2$ & NRG4 & Neuregulin 4 & $\begin{array}{l}\text { The neuregulins, including NRG4, activate } \\
\text { type-1 growth factor receptors to initiate } \\
\text { cell-to-cell signaling through tyrosine } \\
\text { phosphorylation }\end{array}$ & $\begin{array}{l}\text { Common variant association with } \\
\text { serum urate levels }\end{array}$ & (50) \\
\hline
\end{tabular}


TABLE 1 | Continued

\begin{tabular}{|c|c|c|c|c|c|}
\hline $\begin{array}{l}\text { Genomic } \\
\text { location }\end{array}$ & $\begin{array}{l}\text { Candidate } \\
\text { gene }^{\star}\end{array}$ & $\begin{array}{l}\text { Protein encoded by } \\
\text { candidate gene }\end{array}$ & Function (if known) provided by RefSeq & $\begin{array}{l}\text { Genetic association with } \\
\text { gout/hyperuricemia }\end{array}$ & References \\
\hline $1 q 21.1$ & PDZK1 & $\begin{array}{l}\text { PDZ domain containing } \\
1\end{array}$ & $\begin{array}{l}\text { PDZ domain-containing molecules bind to and } \\
\text { mediate the subcellular localization of target } \\
\text { proteins. Single nucleotide polymorphisms in } \\
\text { this gene may be associated with metabolic } \\
\text { syndrome, and overexpression of this gene } \\
\text { may play a role in drug resistance of multiple } \\
\text { myeloma }\end{array}$ & $\begin{array}{l}\text { Common variant association with } \\
\text { serum urate levels }\end{array}$ & $(50,57)$ \\
\hline $1 \mathrm{q} 22$ & $P K L R$ & $\begin{array}{l}\text { Pyruvate kinase, liver } \\
\text { and RBC }\end{array}$ & $\begin{array}{l}\text { The protein encoded by this gene is a pyruvate } \\
\text { kinase that catalyzes the transphosphorylation } \\
\text { of phohsphoenolpyruvate into pyruvate and } \\
\text { ATP, which is the rate-limiting step of glycolysis. } \\
\text { Defects in this enzyme, due to gene mutations } \\
\text { or genetic variations, are the common cause of } \\
\text { chronic hereditary nonspherocytic hemolytic } \\
\text { anemia (CNSHA or HNSHA) }\end{array}$ & $\begin{array}{l}\text { Common variant association with } \\
\text { serum urate levels }\end{array}$ & (50) \\
\hline $17 q 25.1$ & PRPSAP1 & $\begin{array}{l}\text { Phosphoribosyl } \\
\text { pyrophosphate } \\
\text { synthetase associated } \\
\text { protein } 1\end{array}$ & Unknown & $\begin{array}{l}\text { Common variant association with } \\
\text { serum urate levels }\end{array}$ & (50) \\
\hline $12 q 24.13$ & PTPN11 & $\begin{array}{l}\text { Protein tyrosine } \\
\text { phosphatase, } \\
\text { non-receptor type } 11\end{array}$ & $\begin{array}{l}\text { The protein encoded by this gene is a member } \\
\text { of the protein tyrosine phosphatase (PTP) } \\
\text { family which regulate a variety of cellular } \\
\text { processes including cell growth, differentiation, } \\
\text { mitotic cycle, and oncogenic transformation. } \\
\text { Mutations in this gene are a cause of Noonan } \\
\text { syndrome as well as acute myeloid leukemia }\end{array}$ & $\begin{array}{l}\text { Common variant association with } \\
\text { serum urate levels }\end{array}$ & (50) \\
\hline $4 p 16.1$ & SLC2A9 & GLUT9 & $\begin{array}{l}\text { This gene encodes a member of the SLC2A } \\
\text { facilitative glucose transporter family. Members } \\
\text { of this family play a significant role in } \\
\text { maintaining glucose homeostasis. The } \\
\text { encoded protein may play a role in the } \\
\text { development and survival of chondrocytes in } \\
\text { cartilage matrices }\end{array}$ & $\begin{array}{l}\text { Multiple common variant associations } \\
\text { with serum uric acid levels, renal } \\
\text { overload gout, renal under-excretion } \\
\text { gout and overall risk of gout. Low } \\
\text { frequency variants associated with } \\
\text { renal hypouricemia } 2\end{array}$ & $\begin{array}{l}(45-51,54- \\
56,58-77)\end{array}$ \\
\hline $10 q 21.2$ & SLC16A9 & $\begin{array}{l}\text { Solute carrier family } 16 \\
\text { member } 9\end{array}$ & Unknown & $\begin{array}{l}\text { Common variant association with } \\
\text { serum urate levels }\end{array}$ & (50) \\
\hline $6 p 22.2$ & SLC17A1 & NPT1 & $\begin{array}{l}\text { Sodium-dependent phosphate transport } \\
\text { protein } 1 \text { is a protein encoded by the SLC17A1 } \\
\text { gene }\end{array}$ & $\begin{array}{l}\text { Multiple common variant associations } \\
\text { with serum uric acid levels and gout } \\
\text { risk }\end{array}$ & $\begin{array}{l}(45,48,50 \\
53,56,78- \\
80)\end{array}$ \\
\hline $6 \mathrm{p} 22.2$ & SLC17A3 & NPT4 & $\begin{array}{l}\text { The protein encoded by this gene is a } \\
\text { voltage-driven transporter that excretes } \\
\text { intracellular urate and organic anions from the } \\
\text { blood into renal tubule cells. The longer isoform } \\
\text { is a plasma membrane protein with transporter } \\
\text { activity while the shorter isoform localizes to the } \\
\text { endoplasmic reticulum }\end{array}$ & $\begin{array}{l}\text { Multiple common variant associations } \\
\text { with serum uric acid levels. Rare } \\
\text { loss-of-function variants found in } \\
\text { patients with hyperuricemia }\end{array}$ & $(50,53,81)$ \\
\hline
\end{tabular}


TABLE 1 | Continued

\begin{tabular}{|c|c|c|c|c|c|}
\hline $\begin{array}{l}\text { Genomic } \\
\text { location }\end{array}$ & $\begin{array}{l}\text { Candidate } \\
\text { gene* }^{*}\end{array}$ & $\begin{array}{l}\text { Protein encoded by } \\
\text { candidate gene }\end{array}$ & Function (if known) provided by RefSeq & $\begin{array}{l}\text { Genetic association with } \\
\text { gout/hyperuricemia }\end{array}$ & References \\
\hline $11 \mathrm{q} 13.1$ & SLC22A11 & OAT4 & $\begin{array}{l}\text { The protein encoded by this gene is involved in } \\
\text { the sodium-independent transport and } \\
\text { excretion of organic anions. OAT4 is an integral } \\
\text { membrane protein and is found mainly in the } \\
\text { kidney and in the placenta }\end{array}$ & $\begin{array}{l}\text { Multiple common variant associations } \\
\text { with serum uric acid levels }\end{array}$ & $\begin{array}{l}(45,47,50, \\
54)\end{array}$ \\
\hline $11 \mathrm{q} 13.1$ & SLC22A12 & URAT1 & $\begin{array}{l}\text { The protein encoded by this gene is a member } \\
\text { of the organic anion transporter (OAT) family, } \\
\text { and it acts as a urate transporter to regulate } \\
\text { urate levels in blood. This protein is an integral } \\
\text { membrane protein primarily found in epithelial } \\
\text { cells of the proximal tubule of the kidney. An } \\
\text { elevated level of serum urate, hyperuricemia, is } \\
\text { associated with increased incidences of gout, } \\
\text { and mutations in this gene cause renal } \\
\text { hypouricemia type } 1\end{array}$ & $\begin{array}{l}\text { Multiple common variant associations } \\
\text { with serum uric acid levels, renal } \\
\text { overload gout, renal under-excretion } \\
\text { gout and overall risk of gout. Low } \\
\text { frequency variants associated with } \\
\text { renal hypouricemia type I }\end{array}$ & $\begin{array}{l}(39,44- \\
46,50,54 \\
56,82-85)\end{array}$ \\
\hline $8 p 21.2$ & STC1 & Stanniocalcin 1 & $\begin{array}{l}\text { This gene encodes a secreted, homodimeric } \\
\text { glycoprotein that is expressed in a wide variety } \\
\text { of tissues and may have autocrine or paracrine } \\
\text { functions. The protein may play a role in the } \\
\text { regulation of renal and intestinal calcium and } \\
\text { phosphate transport, cell metabolism, or } \\
\text { cellular calcium/phosphate homeostasis. } \\
\text { Overexpression of human stanniocalcin } 1 \text { in } \\
\text { mice produces high serum phosphate levels, } \\
\text { dwarfism, and increased metabolic rate. This } \\
\text { gene has altered expression in hepatocellular, } \\
\text { ovarian, and breast cancers }\end{array}$ & $\begin{array}{l}\text { Common variant association with } \\
\text { serum urate levels }\end{array}$ & $(50)$ \\
\hline $5 q 13.2$ & TMEM171 & $\begin{array}{l}\text { Transmembrane } \\
\text { protein } 171\end{array}$ & Unknown & $\begin{array}{l}\text { Common variant association with } \\
\text { serum urate levels }\end{array}$ & $(50)$ \\
\hline $6 p 21.1$ & VEGFA & $\begin{array}{l}\text { Vascular endothelial } \\
\text { growth factor A }\end{array}$ & $\begin{array}{l}\text { This growth factor induces proliferation and } \\
\text { migration of vascular endothelial cells, and is } \\
\text { essential for both physiological and } \\
\text { pathological angiogenesis. Elevated levels of } \\
\text { this protein are found in patients with POEMS } \\
\text { syndrome, also known as Crow-Fukase } \\
\text { syndrome. Allelic variants of this gene have } \\
\text { been associated with microvascular } \\
\text { complications of diabetes } 1 \text { (MVCD1) and } \\
\text { atherosclerosis }\end{array}$ & $\begin{array}{l}\text { Common variant association with } \\
\text { serum urate levels }\end{array}$ & $(50)$ \\
\hline 2p23.1 & $X D H$ & Xanthine oxidase & $\begin{array}{l}\text { Xanthine dehydrogenase belongs to the group } \\
\text { of molybdenum-containing hydroxylases } \\
\text { involved in the oxidative metabolism of purines. } \\
\text { Defects in xanthine dehydrogenase cause } \\
\text { xanthinuria, may contribute to adult respiratory } \\
\text { stress syndrome, and may potentiate influenza } \\
\text { infection through an oxygen } \\
\text { metabolite-dependent mechanism }\end{array}$ & $\begin{array}{l}\text { Rare loss-of-function variants found in } \\
\text { patients with Type I xanthinuria }\end{array}$ & $(86,87)$ \\
\hline
\end{tabular}

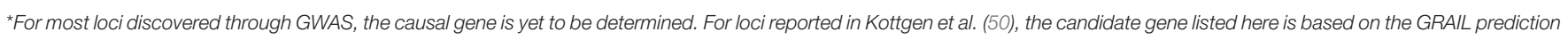
(88). For all others, the candidate gene is that in which the lead associated variant resides.

\section{Urate Excretion Transporters ABCG2/BCRP (ABCG2)}

Genetic variation in human ABCG2, an ATP-driven efflux pump on the apical membrane proximal tubule epithelial cells, has emerged as a major factor in human hyperuricemia and gout risk $(78,110,111)$. Of note, the landmark paper from Ichida and colleagues shows that decreased extra-renal urate excretion caused by ABCG2 dysfunction contributes to clinical hyperuricemia; although paradoxically, urinary urate excretion is also increased by ABCG2 dysfunction implying further roles for regulation of urate levels by this transporter (110). However, ABCG2 is also expressed in the intestine and thus a contribution of gastrointestinal transport cannot be ruled out $(110,112)$.

NPT1 (SLC17A1) and NPT4 (SLC17A3)

GWAS (Genome Wide Association Study) studies have shown that NPT1 and NPT4 are associated with hyperuricemia and 
gout $(38,55,79,99)$. Both NPT1 and NPT4 can transport urate in vitro and are localized on the apical membrane supporting the notion of a role in renal secretion of urate from the apical membrane $(81,113,114)$. However, their relative importance to urate transport in proximal tubule epithelial cells remains incompletely defined.

\section{OAT1 (SLC22A6) and OAT3 (SLC22A8)}

The basolateral entry of urate into renal proximal tubule cells is driven, at least partially, by the outwardly directed gradient for dicarboxylates, which in turn is generated by $\mathrm{Na}^{+}$-dependent uptake. Thus, urate exchange is significantly trans-stimulated by dicarboxylates (115). This is further complicated by the observation that OAT1 and OAT3 appear to exchange urate with divalent anions including dicarboxylates, suggesting that they are suited to basolateral entry of urate $(38,116)$. However, there is no supporting genetic data for a role for these transporters in hyperuricemia.

\section{Genetic Variation Influencing Uric Acid Handling}

As indicated in the former sections on urate resorption and secretion transporters, much is now known about genetic variants contributing to sUA levels and gout through the discovery of rare monogenic disorders affecting uric acid homeostasis, from GWAS, and from candidate gene studies of common variants at the population level. Indeed, there is a strong overlap across genes implicated in monogenic uricemic traits and gout, in a range of genes in addition to those coding for uric acid transporters (Table 1). The largest GWAS to date, by the Global Urate Genetics Consortium (GUGC), studied $>140,000$ subjects of European ancestry and found 28 genetic loci associated with sUA levels and gout (50). The per-allele effect sizes on sUA ranged from 0.035 to $0.379 \mathrm{mg} / \mathrm{dL}$. For gout, each allele contributed small effects on disease risk ranging from a 3\% decrease to a $73 \%$ increase (50). The effects of common genetic variants found to be associated with hyperuricemia and gout in Europeans were of a similar magnitude when tested for association with subjects of other ancestries including African, Indian and Japanese (50). While GWAS have been pivotal in the identification of loci associated with sUA and gout risk, such studies do not provide a direct link to causal genes. For some loci there are obvious and highly likely causal genes, while at other loci the causal gene is far from clear and so GWAS findings should be interpreted with this in mind (117). In addition, genetics is a likely contributor to the well-documented observation that certain ethnic groups have a higher risk than others for hyperuricemia and gout $(118,119)$. Consistent with this notion, GWAS of distinct ethnic groups has revealed some novel loci for gout and uric acid levels $(46,48,49)$. However, in this context, it is worth emphasizing that while hyperuricemia is the central risk factor for gout development, there are other variables in play including age, dietary factors and medications which could be impactful across ethnicities. The heritability of sUA concentrations has been estimated at $42-73 \%$ $(120,121)$, while early twin studies have led to estimates for the heritability of renal urate clearance at $60 \%$ and of fractional excretion of urate to be $87 \%$ (122). Further family studies have found a significant sUA correlation between siblings, parents and offspring though segregation analysis suggests this is likely due to multiple genetic factors rather than a major Mendelian gene (123).

Hypouricemia is defined when a serum urate concentration is less than or equal $2.0 \mathrm{mg} / \mathrm{dL}$ and is reported to occur in $0.8 \%$ of hospitalized patients and $0.2 \%$ of the general population (124). However, it is possible that the prevalence of hypouricemia is actually higher but undiagnosed (125). Hypouricemia can be associated with decreased fractional excretion of uric acid and increased xanthine excretion (e.g., hereditary xanthuria caused by an autosomal recessive deficiency of $X D H$; (126). More typically, hypouricemia is associated with high fractional excretion of uric acid due to genetic causes; including mutations in genes such as SLC22A12 (URAT1) $(39,127)$ and SLC2A9 (GLUT9) $(62,84)$ or factors such as uricosuric usage, renal tubulopathy, neoplasias, and other conditions $(124,127)$. The majority of individuals with hypouricemia are asymptomatic which suggests that it is potentially safe to lower sUA levels to $<1 \mathrm{mg} / \mathrm{dL}$ although clinical management aims at maintaining sUA levels of 4-6 mg/dL. However, nephrolithiasis and exercise induced renal failure (EIRF) have been reported in individuals with mutations in either the SLC22A12 (URAT1) or SLC2A9 (GLUT9) but not XDH (XO) genes $(82,128,129)$. The underlying mechanism is unclear and hypotheses include: (1) acute urate nephropathy caused by increased urate production during exercise, culminating in its intratubular precipitation; (2) ischaemic renal hypoperfusion secondary to vasoconstriction of the renal vessels, mediated by the production of oxygen free radicals during exercise or; (3) the accumulation of anions not eliminated in patients with URAT1 or GLUT9 gene mutations exerts a toxic tubular effect leading to acute tubular necrosis.

\section{HYPERURICEMIA AND GOUT}

Hyperuricemia is commonly defined as a serum urate concentration $>6.8 \mathrm{mg} / \mathrm{dL}$, based on the in vivo solubility of urate above which crystal deposition may occur leading to gout. However, it should be noted that alternative definitions of hyperuricemia are sometimes applied, a factor which needs to be considered when attempting comparative analysis of published data (17). The aqueous solubility of uric acid (6.8 $\mathrm{mg} / \mathrm{dL}$ ) is relatively low when compared to normal range of serum concentrations, and therefore a modest increase can elevate the risk of monosodium urate (MSU) crystal formation and precipitation, notably in the joints and urine reviewed in Chhana et al. (130).

Not all individuals with hyperuricemia go on to develop gout and therefore gout represents a subset of individuals with symptomatic hyperuricemia (131). Although sustained hyperuricemia is a prerequisite of crystal formation, it is not possible to accurately predict which individuals will go on to develop gout, even for those with very high sUA (reviewed in (132)). There is no global consensus on approaches for asymptomatic hyperuricemia nor in response to acute gout attacks, with different strategies advocated by national 
or international guidelines (133), which range from reactive approaches to active sUA management such as that employed by the Japanese (18, 134-136).

The process of crystal deposition leading to gout is reversible by means of reducing sUA levels below its saturation point and it can be surmised that the rate of crystal reduction will be modulated by both the total crystal load and reduction in sUA (reviewed in (137)). While rapid dissolution of crystal deposits may be desirable in therapeutic sense, urate lowering therapy (ULT) initiation generally leads to increased flare rate and associated pain, potentially as a direct consequence of urate crystal dissolution leading to the removal of a protein deposit protecting the underlying surface from attack by inflammatory cells (reviewed in (138)). Indeed, the increased flare rate when initiating ULT has been hypothesized to underpin the reported low levels of patient compliance $(139,140)$ highlighting the need for appropriate prophylaxis in the first few months of the initiation phase $(141,142)$; a consideration reflected in EULAR guidelines which recommend prophylaxis for the first 6 months of therapy (18). It is worth noting that treatment with antiinflammatories alone may modulate the acute inflammatory response to crystals but it is unlikely to alter crystal deposition and ongoing joint damage. As a result, the patient may be unaware of progressive tophi formation and destruction of cartilage and bone. Better understanding of the extent of crystal deposition is being obtained with the advent of advanced imaging modalities including MRI, ultrasound and CT (143). MSU crystals are found in the synovial fluid in 12.5$90 \%$ of gout patients during otherwise asymptomatic phases, suggestive of ongoing inflammation and damage (144). Clinical observations confirm that dissolution of crystals by appropriate sUA lowering treatment results in reduction and ultimately elimination of chronic inflammation $(145,146)$. Indeed, recently updated EULAR recommendations (18) now advocate active management of urate levels from the first presentation of acute gouty flares at $<6 \mathrm{mg} / \mathrm{dL}$ (or $<5 \mathrm{mg} / \mathrm{dL}$ in those with chronic, tophaceous gout) together with improved patient education, including the importance of compliance with longterm treatment, and appropriate pain prophylaxis.

Uric acid urolithiasis refers to the development of a stone or calculus composed of significant amounts of urate in the renal pelvis, ureter, or bladder and are reported to account for $5.0-16.5 \%$ of all kidney stones (reviewed in (147-149)). Uric acid crystals may initiate calcium oxalate precipitation by the induction of heterogeneous nucleation. The glomerular filtrate of blood is usually acidified by the kidneys from a $\mathrm{pH}$ of approximately 7.4 to approximately 6.0 in the urine although this may vary from 4.5 to 8.0 depending on the individual. Accordingly, uric acid solubility is modulated as a function of its weakly acidic $\mathrm{pK}_{\mathrm{a}}$ and hence, individuals with more acidic urine ( $\mathrm{pH}$ 5.5) are more likely to have increased uric acid stone formation than individuals with a normal $\mathrm{pH}$ range $\mathrm{pH} 6.0-$ 6.5) (reviewed in (147)). Urinary alkalinisztion should therefore reduce stone growth/recurrence, and promote stone dissolution (reviewed in (2)). Up to $20 \%$ of patients with gout develop kidney stones although stone formation may also occur in patients with normal urinary and serum levels of urate (reviewed in
(147)). MSU crystal deposits have been detected in the renal medulla of patients with gout and furthermore renal function has been shown to be improved after successful urate-lowering treatment in gout patients (reviewed in (150)). This implies that the presence of MSU crystals in the kidneys and the associated inflammation may contribute to renal insufficiency. Hence, urate crystal elimination may contribute to improved renal function and reduce kidney injury or disease.

\section{EPIDEMIOLOGY OF HYPERURICEMIA AND ASSOCIATED COMORBIDITIES}

In addition to the previously mentioned increase in the prevalence of hyperuricemia and gout, cross-sectional casecontrol studies have found hyperuricemia to be comorbid with multiple common conditions, including cardiovascular events such as coronary artery disease and hypertension (151-153), chronic kidney disease $(152,154)$ or type 2 diabetes (reviewed in $(155,156))$. However, it is unknown whether hyperuricemia is a causal factor in the development of these conditions, is driven by the same risk factors, or if it is a consequence of the manifestation of these disorders. Unless it is directly causal, uric acid lowering is unlikely to be a successful strategy for the treatment of these co-morbid diseases.

If the genetic determinants of hyperuricemia are also associated with the risk of a disease, this provides evidence for causality for hyperuricemia for that disease. This reasoning underpins Mendelian randomization whereby naturally occurring genetic variants are used as instrumental variables to estimate the causal effect on a trait. As many of the common genetic determinants of uric acid levels have been revealed through GWAS, these instrumental variables have been used in several studies to test for the causality of uric acid in multiple disorders including sudden cardiac death (157), blood pressure (158), coronary heart disease (159), chronic kidney disease progression (102), type 2 diabetes $(160,161)$, triglyceride levels (162) or adiposity (163). However, it remains a challenge to identify the underlying causal mechanisms behind any such associations given the large number of these instruments, with each contributing just a small effect on uric acid levels, across multiple genes. An additional consideration is that many patients with hyperuricemia and gout who develop major cardiovascular and renal events also possess several other known traditional risk factors which may be potentially confounding.

A recent review of the evidence for causality of hyperuricemia in disease concluded that the only robust evidence to date, based on both randomized clinical trials and/or Mendelian randomization, is that of a causal role for hyperuricemia in gout and nephrolithiasis (164). A limitation of the Mendelian randomization approach however is that the genetic instruments for serum urate levels may not adequately capture any effect of intracellular urate levels on disease so this should be considered when interpreting any negative findings (165). Trials seeking to determine whether urate-lowering therapy may influence outcomes in other diseases have been performed in small cohorts 
for short durations $(166,167)$; we would like to see replication in larger cohorts with longitudinal assessment.

\section{Cardiovascular Disease}

Over the last decade, we have seen an accumulating body of evidence which implicates gout and/or uric acid elevation as an independent predictor for hypertension, atrial fibrillation and cardiovascular disease $(150,155,168-171)$. However, clearly not all patients with hyperuricemia go on to develop cardiovascular disease and many of those who do also exhibit one or more other established risk factors.

Clinical observations showing an association between high uric acid levels and hypertension are further corroborated in the pediatric and adolescent populations where blood pressure values are significantly elevated ( $>95$ th percentile) in the presence of sUA levels of $>5.5 \mathrm{mg} / \mathrm{dL}(172-174)$. Furthermore, independently of the pharmacological mechanism (both XO inhibitor and uricosuric), reduction of sUA has been shown to lower blood pressure in early primary hypertension in adolescents $(173,175)$. This finding is supported by the observation that the nonsynonymous variant in SLC2A9, rs16890979 (Val253Ile) is significantly associated both with a reduction in both uric acid and in blood pressure in an Amish cohort exposed to sodium-controlled diets (158). Finally, a number of studies have confirmed that people with elevated sUA are at risk of having high blood pressure, even if they otherwise appear to be perfectly healthy $(152,176)$ and reviewed in Richette et al. (150).

Both experimental and clinical evidence suggests that deleterious effects of high uric acid levels on cardiovascular disease may occur at the vascular level. For example, it has been shown that high levels of uric acid are associated with lowgrade inflammatory state and vascular activation of the reninangiotensin system (reviewed in (155)). Clinical data further supports the notion of endothelial dysfunction associated with sUA elevation and chronic inflammation (177) and reviewed in Richette et al. (150). An increasing number of researchers have suggested that XO plays an important role in various forms of ischemic and other types of tissue and vascular injuries, inflammatory diseases, and chronic heart failure (reviewed in (178)). Interestingly, common variants in the $\mathrm{XDH}$ gene are associated with blood pressure and hypertension although these findings need to be further substantiated (179). Accordingly, XO inhibitors may have more profound effects through restoration of endothelial function as opposed to a lowering of sUA levels per se. However the studies were limited in size and careful metaanalyses may be warranted (reviewed in (170)). This question of whether XO inhibitors have potential therapeutic benefit in cardiovascular disease, has been the subject of a number of clinical investigations $(175,180-183)$. However, the impact of early intervention in patients with asymptomatic hyperuricemia (with or without crystal deposition) on vascular outcomes has not been definitively demonstrated (184). Given the long history of this class of drugs, in particular allopurinol, it is interesting to speculate on the potential value of mining medical record databases to understand the implications of long term urate lowering, although interpretation of such data may be undermined by lack of insight into patient adherence to therapy and by suboptimal dose management (185-187). Mendelian randomization studies have produced mixed results-in subjects from the Ludwigshafen Risk and Cardiovascular Health Study, a higher burden of variants associated with uric acid levels was associated both with an increased risk of cardiovascular death and sudden cardiac death (157). Meanwhile, White et al demonstrated that the evidence for causality of urate levels in coronary artery disease is dependent on the model used. Using the Egger method for Mendelian randomization, which accounts for unmeasured pleiotropy of the instrumental variables, they find that the evidence for causality using traditional Mendelian randomization approaches may be inflated (159). Finally, by excluding instrumental variants shown to be pleiotropic, Keenan et al found a lack of significant association between 14 uratespecific variants and risk of coronary heart disease, ischemic stroke and heart failure (188).

\section{Kidney Disease}

It is well accepted that hyperuricemia is associated with crystalrelated pathologies such as nephrolithiasis. High plasma urate levels are associated with an increased risk of acute kidney injury (AKI) $(154,189,190)$. Studies further suggest potential for renal injury in a manner analogous to cardiovascular outcomes due to renal vasoconstriction via inflammation, endothelial dysfunction and renin-antiotensin system activation (reviewed in $(191,192)$ ). Interestingly, sUA reduction has been found to improve renal function in patients irrespective of gout presentation and a more comprehensive investigation of reno-protective potential for urate lowering therapies may be warranted (193-199). A small Mendelian randomization study supports the hypothesis that hyperuricemia, driven by an instrumental variant in SLC2A9, is causal in chronic kidney disease progression (102). Contrary to expectations, a study using a genetic risk score composed of five instrumental variants in uric acid transporters was significantly associated with better (rather than worse) renal function (200). The authors speculate however that it is the activity of these uric acid transporters, rather than the serum urate levels, that are having the protective effect on renal function and that using fractional excretion of uric acid as the exposure in a Mendelian randomization study, instead of serum urate, would help to determine if this is the case.

Clinical data suggests that most gout sufferers under-excrete uric acid leading to a corresponding increase in sUA levels $(78,110,201)$. The kidneys play a major role in the regulation of serum uric acid levels given the extensive handling of urate by the renal proximal tubules (as discussed in the physiology section); which adds to the debate whether hyperuricemia merely acts as an indicator of renal dysfunction or has a causative role. Accordingly, there is a wealth of clinical data which supports the hypothesis that hyperuricemia is both a predictor of onset and a modulator of progression for both acute kidney injury and for chronic kidney disease (CKD), the latter of which in particular is increasingly recognized as a global health problem $(13,16,202-207)$. In contrast, other epidemiological studies have reported no significant relationship between hyperuricemia and CKD progression (208) and therefore the debate continues. 


\section{Type 2 Diabetes}

In population-based studies, hyperuricemia was shown to be an independent risk factor for developing Type 2 diabetes (T2D) $(60,209)$. In cardiovascular disease, there is a complex interplay of factors with obesity, insulin resistance and diuretic use all being associated with increased urate reabsorption confounding efforts to determine the relationship between sUA levels, kidney function and diabetes, in addition to other common co-morbidities or complications such as peripheral neuropathy (210-212). Consistent with the notion of addressing hyperuricemia to impact on symptoms, there are studies suggesting ULT beneficially modulates diabeticassociated phenotypes (194, 213-216). Despite this, Mendelian randomization studies conclude that uric acid is not causal in type 2 diabetes $(161,188)$, though the accompanying commentary for the former again highlights some of the limitations of Mendelian randomization using instruments that are context specific which may not represent what is happening at the physiological level (109).

The development of sodium glucose co-transporter 2 (SGLT2) inhibitors for the treatment of diabetes has rekindled interest and debate into the role of sUA in diabetes and CKD. SGLT2 inhibitors act via the kidneys in an insulin-independent manner to improve glycemic control but also reduce sUA levels without obvious uric acid nephrolithiasis $(106,216,217)$. In one small study, it was shown that SGLT2 inhibitor treatment contributed to decreased plasma UA levels together with increased FEUA levels (109). It is not clear how SGLT2 inhibition impacts on uricosuria although one possibility could be through effects on GLUT9 via induction of glycosuria which in turn would contribute to higher levels of urate exchange across the apical membrane of tubular cells into the urine $(105,106,218)$.

Taken together, these studies indicate that hyperuricemia is commonly observed in patients together with co-morbidities such as hypertension, cardiovascular disease, CKD and T2D. To date there are no conclusive data that modulation of uric acid levels reduces that risk (17). Therefore, there is no consensus on therapeutic approaches for these conditions in the context of hyperuricemia and indeed ULT are not indicated for these conditions. Should further studies support the notion that chronic hyperuricemia is associated with increased risk of these debilitating co-morbidities, and furthermore if active reduction of sUA levels proves to be protective, we wonder if this will enable a shift in clinical practice toward proactively monitoring of uric acid levels at least in the first instance.

\section{LAUNCHED (MARKETED AND WITHDRAWN) DRUGS FOR HYPERURICEMIA}

There are several approved ULT drugs which fall into three main classes: reduction of uric acid synthesis (xanthine oxidase inhibitors); increasing uric acid excretion (uricosurics, e.g., URAT1 inhibitors); and enabling systemic metabolic hydrolysis of uric acid (urolytics, e.g., recombinant uricases) (Figure 5, Table 2).

\section{Xanthine Oxidase Inhibitors (XOi)}

The inhibition of xanthine oxidase reduces endogenous production of uric acid and thus lowers sUA levels. Xanthine oxidase inhibitors, in the form of allopurinol, were the first class of urate lowering therapy to reach the market and remain the first line therapy for hyperuricemia and gout. Inhibitors fall into two main classes: the classical purine analogs (including allopurinol) and more recently developed non-purine analog compounds such as febuxostat and topiroxostat.

\section{Allopurinol}

Allopurinol, a structural isomer of hypoxanthine, has been the cornerstone of hyperuricemia and gout clinical management since its introduction in 1966; and indeed remains the current standard of care despite some tolerability issues and reportedly low patient compliance (reviewed in (219)). It should be noted that patient adherence issues may simply reflect the high prevalence of allopurinol use over other urate lowering therapies, rather than reflecting any specific property of allopurinol.

Allopurinol itself is a relatively weak competitive $\mathrm{XO}$ inhibitor and is rapidly metabolized to the more potent oxypurinol, an isostere of xanthine, which is then renally cleared. Clinically, allopurinol is used for reducing uric acid levels particularly in the context of gouty arthritis and kidney stones/lithiasis. Additional indications include genetically linked enzyme disorders associated with uric acid overproduction, such as Lesch-Nyhan syndrome (HGPT deficiency), and myeloproliferative disease (tumor lysis syndrome). Allopurinol has been proposed to possess additional pharmacology, such as decreasing blood pressure and creatinine levels, which supports the notion that XO inhibition may have effects independent of urate lowering (220) and reviewed further in Richette et al. (150).

Although allopurinol remains the most frequently prescribed ULT, studies have suggested that less than $50 \%$ of patients taking the drug achieve a sUA level $<6 \mathrm{mg} / \mathrm{dL}$ at an allopurinol dose of $300 \mathrm{mg} /$ day $(221,222)$ and reviewed further in (138). A more recent study by Jennings suggests that of 400 patients, $36 \%$ required allopurinol up-titration to achieve sUA levels of $<6$ $\mathrm{mg} / \mathrm{dL}$ (223). The recommended starting dose of allopurinol in the USA is $100 \mathrm{mg} /$ day with incremental dose increases each 24 weeks, up to $800 \mathrm{mg} / \mathrm{day}^{1}$ (900 mg/day in Europe (224)), until the target of sUA $<6 \mathrm{mg} / \mathrm{dL}$ is achieved $(134,135)$. However, in routine clinical practice, patients are often started at $100 \mathrm{mg}$ daily and titrated up to $300 \mathrm{mg}$ daily only, with the result that studies report between 36 and $50 \%$ of patients fail to achieve target sUA levels of less than $6 \mathrm{mg} / \mathrm{dL}(223,225)$ and discussed further in Shahid and Singh (226).

Allopurinol has been associated with several adverse effects including gastrointestinal effects, rash and Stevens-Johnson's syndrome (227). In addition, allopurinol hypersensitivity syndrome (AHS) is a rare but potentially lethal risk for $2-8 \%$ of patients (228). Complications can also arise when patients have renal impairments which may require dose reductions (229). Some drug interactions with ampicillin or amoxicillin are known to increase the incidence of skin rash when used in combination

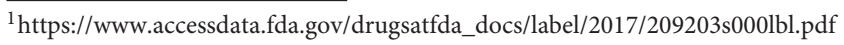




\section{Purine-based XO inhibitors}<smiles>O=c1[nH]cnc2[nH]ncc12</smiles>

allopurinol 1966-present<smiles>O=c1[nH]c(=O)c2cn[nH]c2[nH]1</smiles>

oxypurinol
Non-purine XO inhibitors<smiles>Cc1nc(-c2ccc(OCC(C)C)c(C#N)c2)sc1C(=O)O</smiles>

febuxostat 2009-present<smiles>N#Cc1cc(-c2n[nH]c(-c3ccncc3)n2)ccn1</smiles>

topiroxostat 2013-present

\section{URAT1 inhibitors}<smiles>CCc1oc2ccccc2c1C(=O)c1cc(Br)c(O)c(Br)c1</smiles>

benzbromarone 1970s-2003<smiles>O=C(O)CSc1nnc(Br)n1-c1ccc(C2CC2)c2ccccc12</smiles>

FIGURE 5 | Structures of launched (marketed and withdrawn) drugs for the management of hyperuricemia. Purine-based (allopurinol and oxypurinol) and non-purine based (febuxostat and topiroxostat) XO inhibitors are shown with dates of approval for clinical use. URAT1 inhibitors are represented by benzbromarone (withdrawn in 2003) and lesinurad (RDEA594).

TABLE 2 | Launched (marketed and withdrawn) therapies for hyperuricemia/gout.

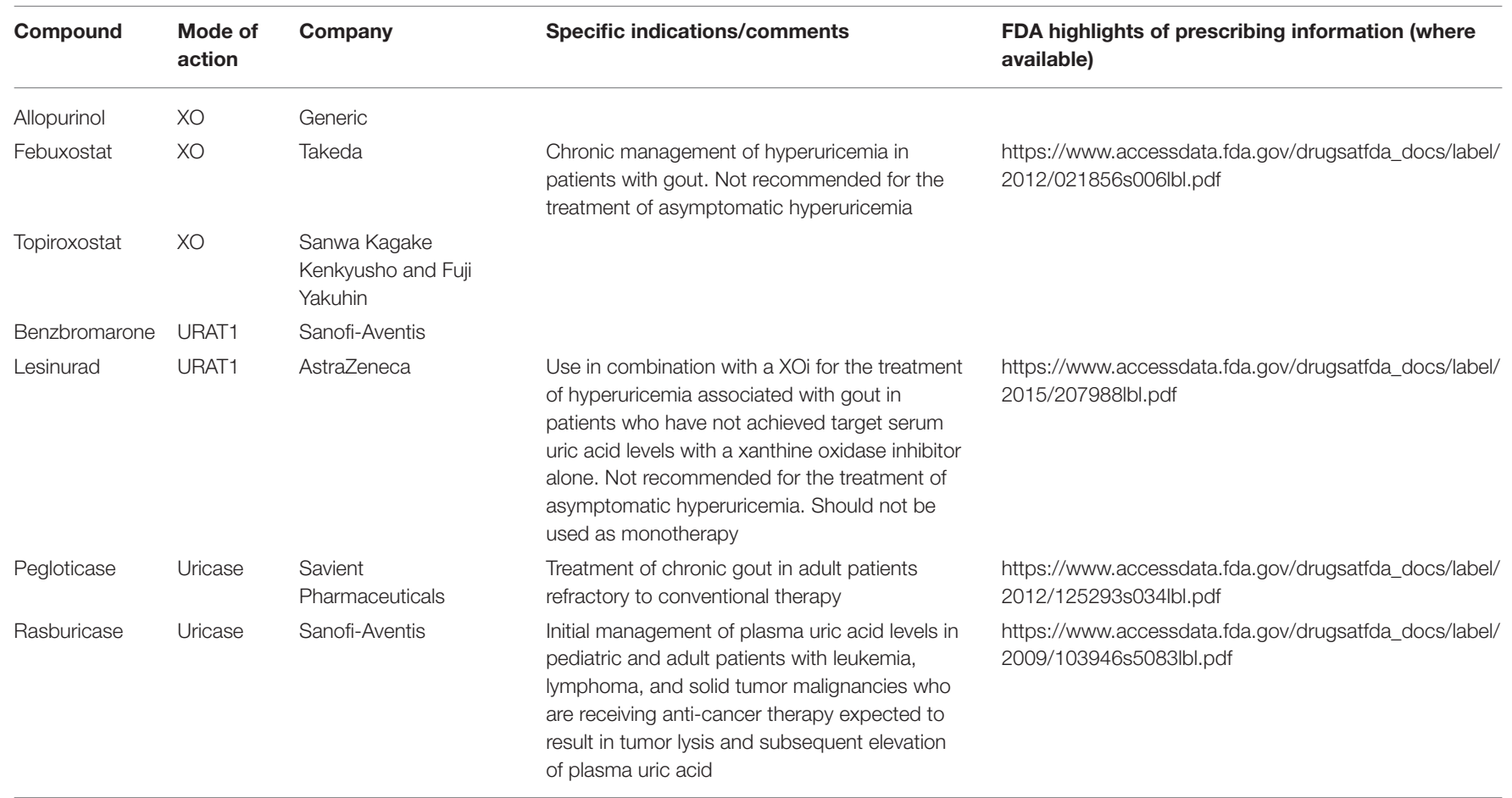

XO(i), xanthine oxidase (inhibitor). 
(230). More recently, structural understanding of XO together with rational drug development has enabled the discovery of novel, chemically diverse and more potent XO inhibitors such as febuxostat.

\section{Febuxostat}

Febuxostat is a selective, non-purine, inhibitor of XO approved by the FDA in 2009, for management of patients with hyperuricemia in patients with gout but not for asymptomatic hyperuricemia ${ }^{2}$ Febuxostat is approved for use at doses of 40 and $80 \mathrm{mg} /$ day in the USA; and up to $120 \mathrm{mg}$ /day in Europe and 10-60 mg/day in Japan (18). Febuxostat has a reported $\mathrm{IC}_{50}$ of $1.8 \mathrm{nM}$, which is significantly more potent than allopurinol ( $\mathrm{IC}_{50}$ $7.8 \mu \mathrm{M}$ ), and consequently has been shown to be more efficacious at doses of 80 or $120 \mathrm{mg}$ for achieving target urate levels of $<6$ $\mathrm{mg} / \mathrm{dL}$ vs. allopurinol at 100-300 mg daily (231). However, at the doses licensed for use in the USA, only $48-67 \%$ of those receiving febuxostat reach sUA levels $<6 \mathrm{mg} / \mathrm{dL}$ (232).

Febuxostat clearance is predominantly via hepatic metabolism which suggests the potential at least for broader prescribing with respect to impaired renal function though this has not been fully assessed in the clinic. In addition, febuxostat has been reported to have fewer drug-drug interactions than allopurinol and is better tolerated in patients with AHS (233). It also has been reported to be a strong ABCG2 inhibitor, though the potential impact of this is not yet clear (234).

Interestingly, gout flares on commencement of treatment have been reported to be more frequent with febuxostat than with allopurinol, likely due to the more rapid and pronounced sUA reduction, an observation which has interesting implications with respect to considering the rate of sUA decrease for ULT strategies (235). While febuxostat is an option for patients with prior rash or hypersensitivity reaction to allopurinol, it is worth noting that a hypersensitivity reaction has also been reported with febuxostat (236). More recently, febuxostat was found to be noninferior to allopurinol with respect to rates of adverse cardiovascular events while all-cause mortality and cardiovascular mortality were reported to be higher with febuxostat than with allopurinol (237).

Clinical uptake of febuxostat has been relatively poor, likely in most part due to the cost compared to the generic allopurinol, with cost per tablet of $\$ 7$ for febuxostat vs. $\$ 0.20-0.60$ for allopurinol in the USA $(226,238,239)$. In line with this, febuxostat has been suggested as second line to allopurinol in updated care guidelines (18).

\section{Topiroxostat}

Topiroxostat (FYX-051) is a structurally distinct, non-purine, selective XO inhibitor which was approved for use only in Japan in 2013 and was co-developed and marketed as Uriadec/Topiloric by Sanwa Kagake Kenkyusho and Fuji Yakuhin. It is available in oral tablets of 20,40, and $60 \mathrm{mg}$ doses and the general recommendation is to start with an initial $20 \mathrm{mg}$ dose twice daily with the maximum approved dose being $80 \mathrm{mg}$ twice daily with clinical efficacy reported at $120 \mathrm{mg}$ /day $(240,241)$. Topiroxostat

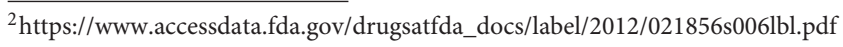

has been shown to inhibit xanthine oxidase via formation of a hydroxylated 2-pyridine metabolite that forms a covalent linkage to the molybdenum via oxygen and also interacts with amino acid residues in the solvent channel $(242,243)$.

\section{Uricosurics}

Studies have suggested that, despite the standard of care for hyperuricemia and gout being focussed on reduction of synthesis by XO inhibitors, the underlying cause of hyperuricemia in a notable subset of patients is due to renal underexcretion of uric acid $(110,244)$. This suggests the application of uricosuric agents to increase renal urate excretion to be a rational approach for the treatment of hyperuricemia. However, by enhancing the renal clearance of uric acid, uricosurics may increase the risk of renal adverse events (e.g., nephrolithiasis) (reviewed in (245)).

Historically, several drugs, including probenecid, sulfinpyrazone, fenofibrate and losartan, were serendipitously discovered to have uricosuric properties although the underlying pharmacology was not initially understood (35, 139, 246). Likewise, benzbromarone, the first drug specifically developed for its uricosuric properties, was discovered and developed without any understanding of its pharmacology at a molecular level (reviewed in (247)). More recently, the identification of the URAT1 transporter and its role in urate re-uptake from the proximal tubule has shed light on the pharmacology of these compounds and enabled the development of a new generation of specifically targeted uricosuric compounds (39). Interestingly other transporters (e.g., GLUT9/SLC2A9) have also been genetically linked with urate homeostasis and may provide further targets for novel uricosuric drug development in the future $(39,59,218)$.

Currently uricosurics are recommended as a second line therapy when target sUA levels are not reached, particularly as add-on therapies in combination with XO inhibitors (134, 135). Combination therapy with allopurinol and benzbromarone has been suggested to provide enhanced urate lowering and potentially more rapid resolution of tophi (145); a concept which has been applied to other XOi and uricosuric combinations.

\section{Probenencid}

Probenecid was originally introduced to prolong the action of antibiotics by reducing their renal clearance and functions as a non-selective inhibitor of organic anion transporters (reviewed in (248)). URAT1 has now been demonstrated to be one of the molecular targets of probenecid and, while its lack of selectivity and subsequent potential for drug-drug interactions limit its clinical use as a uricosuric, it perhaps represents the prototypical URAT1 inhibitor and uricosuric mechanism for ULT $(92,249)$.

\section{Benzbromarone}

Benzbromarone, first marketed in the 1970s, was the first compound specifically introduced as a uricosuric agent. The molecular basis of its pharmacology was not understood at the time of its introduction but it has subsequently been shown to be a potent URAT1 inhibitor ( $\mathrm{IC}_{50} 22 \mathrm{nM}$ ) (96). Benzbromarone is effective as a single agent ULT with studies showing that $92 \%(22 / 24$ patients) of gout patients reached target levels of 
serum urate from a $200 \mathrm{mg} /$ day dose (250). However, it should be noted that in a subsequent study, where dose was escalated for both benzbromarone and allopurinol in patients failing to achieve adequate control on the starting dose, both compounds performed equally (251).

Like allopurinol, benzbromarone required dose titration from 50 to $200 \mathrm{mg}$ once daily to achieve maximum efficacy but unlike allopurinol, benzbromarone could be used in patients with renal impairment. Given that uricosuric drug usage increases urate renal excretion, caution was advocated by clinicians where there was history of renal calculi so strategies such as urinary alkalinization to solubilize the uric acid were employed (245, 252).

Benzbromarone was not approved in the USA and was withdrawn from the market in many other countries in 2003 following reported incidents of idiosyncratic hepatotoxicity (reviewed in (247)).

\section{Lesinurad (RDEA594)}

Lesinurad (Zurampic ${ }^{\circledR}$ ) is the first novel uricosuric to reach the market since benzbromarone (94). The primary mechanism of action of lesinurad derives from inhibition of URAT1, although it is also reported to be an inhibitor of OAT4 which could also potentially contribute to its efficacy; however, it is reported to be selective over related transporters such as OAT1 and OAT3 which may avoid some of the drug-drug interaction liabilities of non-selective compounds such as probenecid (94, 253-255, 273).

Following its acquisition by AstraZeneca in 2012, Ardea continued to progress the clinical programme. Phase 2 clinical studies have shown lesinurad to provide additional efficacy as an add-on therapy in individuals with inadequate urate reduction based on XOi's alone (256-258). Therefore, lesinurad was subsequently evaluated in three pivotal phase 3 trials in combination with XOi's; in combination with allopurinol in adults with gout showing inadequate response to allopurinol alone (CLEAR 1 and 2) and in combination with febuxostat in adults with tophaceous gout (CRYSTAL) (258-260).

The CLEAR 1 study demonstrated an increase in the proportion of patients achieving a serum UA level of $<6.0$ $\mathrm{mg} / \mathrm{dl}$ after 6 months (the primary end point) with 54.2 and $59.2 \%$ in the lesinurad $200 \mathrm{mg}$ plus allopurinol and lesinurad $400 \mathrm{mg}$ plus allopurinol groups respectively, compared to $27.9 \%$ in those taking allopurinol alone. This was more broadly reflected across the duration of the trial with serum UA levels being lower at all time points assessed in both groups taking lesinurad plus allopurinol as compared with allopurinol alone. Lesinurad was reported to be generally well tolerated with the AE profile of the $200 \mathrm{mg}$ lesinurad plus allopurinol dose comparable to that of allopurinol alone (73.1 and $68.7 \%$ respectively), while that of $400 \mathrm{mg}$ lesinurad plus allopurinol was slightly higher (77.6\%). Given the uricosuric mechanism of action, renal safety was highlighted as a potential risk and higher incidence of renal-related treatment-emergent adverse events (TEAEs) were observed with lesinurad $400 \mathrm{mg}$ plus allopurinol (10.0\%) compared with the lesinurad $200 \mathrm{mg}$ plus allopurinol and allopurinol-alone groups (3.5 and 4.0\%, respectively). In the lesinurad $400 \mathrm{mg}$ plus allopurinol group a serious renal-related TEAE (renal failure) was reported in 1 patient $(0.5 \%)$. The most common renal-related TEAE was elevations in serum creatinine $\geq 1.5 \times$ baseline which occurred at higher rates in the lesinurad plus allopurinol groups (6.0 and $15.9 \%$ in the $200 \mathrm{mg}$ and $400-\mathrm{mg}$ lesinurad doses respectively) vs. allopurinol alone (1\%). The CLEAR 2 trial showed similar findings with 55.4 and $66.5 \%$ in the lesinurad $200 \mathrm{mg}$ plus allopurinol and lesinurad $400 \mathrm{mg}$ plus allopurinol groups respectively, compared to $23.3 \%$ in those taking allopurinol alone achieving the target serum UA level of $<6.0 \mathrm{mg} / \mathrm{dl}$ after 6 months. Likewise, the profile of renalrelated TEAEs was comparable with lesinurad $400 \mathrm{mg}$ plus allopurinol showing a higher rate (15.0\%) compared with the lesinurad $200 \mathrm{mg}$ plus allopurinol and allopurinol-alone groups (4.9 and 5.9\%, respectively), again was mainly related to elevations in blood creatinine. Similar renal effects were also noted in a monotherapy trial with a $400 \mathrm{mg}$ dose of lesinurad (261).

The CRYSTAL study investigated the safety and efficacy of lesinurad, in combination with febuxostat, in a 12-month trial in patients with tophaceous gout. The primary endpoint serum UA target, of $<5.0 \mathrm{mg} / \mathrm{dl}$ after 6 months, was achieved by significantly more patients with febuxostat plus the addition of lesinurad $400 \mathrm{mg}(76.1 \% ; P<0.0001)$, compared with febuxostat alone $(46.8 \%)$. The $200 \mathrm{mg}$ dose of lesinurad did not show a significant effect on the primary endpoint $(56.6 \% ; P=0.13)$, however, at all other time points assessed, significantly more patients in this group achieved the serum UA target. There was no significant difference in the proportion of patients with complete tophus resolution between groups. However, the lesinurad (200 and $400 \mathrm{mg}$ ) plus febuxostat groups showed a greater reduction in the total target tophi area (50.1 and 52.9\%, respectively) compared to febuxostat alone $(28.3 \%)$. Overall rates of TEAEs were comparable across the group, while renal-related TEAEs were slightly increased in the lesinurad $200 \mathrm{mg}$ plus febuxostat group, and in the lesinurad $400 \mathrm{mg}$ plus febuxostat group (8.5 and $10.1 \%$, respectively) compared with febuxostat (5.5\%), again largely reflecting an increased incidence of elevated serum creatinine levels with lesinurad. No patients in the lesinurad $200 \mathrm{mg}$ plus febuxostat group had a renal-related serious adverse event, while two patients in the lesinurad $400 \mathrm{mg}$ plus febuxostat group (renal failure acute; renal failure chronic) and one patient in the febuxostat group (renal failure acute) had renal-related serious TEAEs.

Ultimately, the $200 \mathrm{mg}$ dose of lesinurad received FDA approval at the end of 2015 for use in combination with a xanthine oxidase inhibitor for the treatment of hyperuricemia associated with gout in patients who have not achieved target serum uric acid levels with a xanthine oxidase inhibitor alone. Its use is contraindicated in patients with severe renal impairment, kidney transplant recipients, patients on dialysis, in tumor lysis syndrome (TLS) or Lesch-Nyhan syndrome) ${ }^{3}$ For more information a number of focused reviews of this compound have recently been published providing a more in-depth description of its profile (262-264).

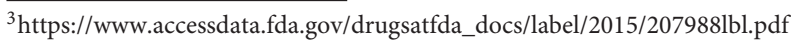




\section{Urate Hydrolysis by Uricases (Pegloticase and Rasburicase)}

Humans, and some primate species, differ from other mammals by the lack of a functional uricase enzyme. Uricase degrades uric acid into the more water soluble allantoin which is then eliminated readily through the kidney. Therefore, therapies based on the intravenous administration of a functional recombinant uricase enzyme have been developed which enable an immediate and significant reduction of sUA levels. Pegloticase, a PEGylated recombinant uricase was approved in 2010 for limited-patient use in the treatment of chronic refractory gout in patients with tophaceous deformities and complications $(265,266)$. The National Institute of Health and Clinical Excellence supports the use of pegloticase as a third line treatment for tophaceous gout in patients where $\mathrm{XO}$ inhibitors and uricosurics are contraindicated $^{4}$; echoed by EULAR and ACR (American College of Rheumatology) guidelines $(18,134,135)$. It is administered in $8 \mathrm{mg}$ biweekly intravenous doses for at least 6 months. Clinical trials demonstrated a $47 \%$ response rate over placebo (266). However, likely due to the very rapid urate reduction caused by administration of pegloticase, its application has been associated with significant prevalence of acute flares. In addition, although pegloticase has been used effectively in the clinic it is also prone to immunogenic infusion reactions with a significant portion of the patients receiving pegloticase developing antibodies within the first few months of treatment (266). In clinical studies, infusion reaction adverse events occurred in $26-41 \%$ of patients including dyspnea, chest discomfort and flushing. These reactions were more common in patients in which significant levels of antibodies to pegloticase had developed. In order to reduce these infusion reactions, pretreatment of patients with antihistamines or corticosteroids is carried out with the risk of complications that can lead to issues in patients with congestive heart failure (266).

A non-PEGylated uricase, rasburicase has also been approved for specifically treating hyperuricemia associated with tumor lysis syndrome as its quick mode of action and short half-life relative to pegloticase ( $8 \mathrm{~h}$ vs. 12 days) aligns well with this particular application (267). As a result, it was approved for the initial management of plasma uric acid levels in pediatric and adult patients with leukemia, lymphoma, and solid tumor malignancies who are receiving anti-cancer therapy expected to result in tumor lysis and subsequent elevation of plasma uric acid. Rasburicase also causes high rates of immunogenic infusion reactions, methemoglobinemia, hemolysis and anaphylaxis in patients which limit its more general use.

\section{EMERGING CLINICAL TREATMENT APPROACHES}

Several factors may have influenced what appears to be a renewed interest in the development of treatments for hyperuricemia and gout in recent years, including: (1) emerging clinical perspective

$\overline{{ }^{4} \text { https://www.nice.org.uk/guidance/ta291 }}$ that gout and hyperuricemia are eminently treatable but undertreated conditions; (2) a growing understanding of relevant urate transporters in the kidney as potential drug targets enabling drug design; (3) observations that support the notion that hyperuricemia might contribute to a range of co-morbidities including hypertension, cardiovascular disease, stroke, type 2 diabetes, obesity, metabolic syndrome hyperlipidemia and chronic kidney disease; (4) adoption in Japan of an aggressive approach to the management of asymptomatic hyperuricemia creating a specific market opportunity.

In this section, we have endeaveoured to identify and discuss candidates which are actively undergoing clinical assessment as either urate lowering therapies or for the control of gout flares (Figure 6, Table 3). Compounds which have not appeared to have advanced in clinical studies over the past 2 years, based on reported activity on Clintrials.gov, have been excluded as these are presumed to have been paused or stopped in clinical development although the rationale for this may not have been disclosed. A few notable examples of such compounds are briefly discussed at the end of the section based on scientific interest e.g., novel chemotypes for existing mechanisms, or a novel mechanism of action.

\section{Uricosuric Compounds Arhalofenate (MBX201)}

Arhalofenate (Cymabay Therapeutics/Metabolex) is the $(R)$ single enantiomer of the racemic drug halofenate that had been originally developed as a PPAR $\gamma$ inhibitor which was assessed in hyperlipidemia and diabetes but has since been repurposed as a gout drug based on urate lowering observations (274). Arhalofenate has been reported to act as a pro-drug which is cleaved in vivo to the active metabolite arhalofenic acid which has uricosuric activity attributable to the weak inhibition of a panel of renal uric acid transporters including URAT1, OAT4 and $\mathrm{OAT} 10^{5}$ Interestingly, arhalofenate appears to have additional effects with respect to reducing the IL- $1 \beta$ signaling cascade in response to monosodium urate crystals, in addition to decreasing triglycerides and enabling insulin sensitization. This has been reported to lead to reduced incidence of flares in patients with gout in a similar manner to colchicine, which also inhibits the release of IL-1 $\beta(272,275,276)$.

The potential for arhalofenate $(600$ and $800 \mathrm{mg}$ ) to reduce flare rate was tested against allopurinol $(300 \mathrm{mg})$ and allopurinol (300 mg) + colchicine $(0.6 \mathrm{mg})$; the efficacy of the compound, as measured by percentage reduction in serum urate and the proportion of patients with a serum UA level of $<6 \mathrm{mg} / \mathrm{dL}$ was included as a secondary outcome (277). Treatment with $800 \mathrm{mg}$ arhalofenate led to a decreased number of gout flares with a 46 and $41 \%$ vs. allopurinol and placebo groups respectively. While allopurinol $(300 \mathrm{mg})+$ colchicine $(0.6 \mathrm{mg})$ showed a numerically greater reduction to arhalofenate $800 \mathrm{mg}$ it was not statistically different. At week 12 the mean reduction in sUA level from baseline was $-12.5 \%$ in the $600 \mathrm{mg}$ arhalofenate group and $-16.5 \%$ in the $800 \mathrm{mg}$ arhalofenate group, compared with $-0.9 \%$ in the placebo group. This compared to $-28.8 \%$ in the

$\overline{{ }^{5} \mathrm{http} / / / \text { ard.bmj.com/content/annrheumdis/71/Suppl_3/450.3.full.pdf }}$ 
<smiles>CC(=O)NCCOC(=O)[C@H](Oc1cccc(C(F)(F)F)c1)c1ccc(Cl)cc1</smiles>

arhalofenate (MBX201)<smiles>O=C(c1cc(Br)c(O)c(Br)c1)N1CCOc2ccncc21</smiles>

URC-102<smiles>COc1ccc(/C=C/C(=O)Nc2ccccc2C(=O)O)cc1OC</smiles>

tranilast<smiles>O=c1[nH]cnc2c(CN3C[C@H](O)[C@@H](CO)C3)c[nH]c12</smiles>

ulodesine (BCX4208)

FIGURE 6 | Selected recent emerging clinical compounds (where structure disclosed). The structures for arhalofenate (MBX201), tranilast, verinurad (RDEA3170), URC-102 and ulodesine (BCX4208) are shown here.

TABLE 3 | compounds currently in development for hyperuricemia/gout.

\begin{tabular}{|c|c|c|c|c|c|c|c|}
\hline Compound & Alias & Target & Company & Website(s) & Phase & $\begin{array}{l}\text { ClinTrials.gov last } \\
\text { ongoing } \\
\text { (recruiting)/completed } \\
\text { activity related to } \\
\text { hyperuricemia/gout. }\end{array}$ & References \\
\hline FYU-981 & & URAT1 & $\begin{array}{l}\text { Fuji Yakuhin, now } \\
\text { co-developing } \\
\text { with Mochida }\end{array}$ & $\begin{array}{l}\text { http://www.mochida.co.jp/english/ } \\
\text { business/ }\end{array}$ & 3 & $\begin{array}{l}\text { Last study completed 2016, } \\
\text { (NCT02416167, last } \\
\text { updated February 2017) }\end{array}$ & $(268,269)$ \\
\hline Arhalofenate & MBX201 & $\begin{array}{l}\text { interleukin-1 } \beta \\
(\mathrm{IL}-1 \beta) \text { modulator, } \\
\text { reported to be a } \\
\text { weak inhibitor of } \\
\text { URAT1, OAT4 and } \\
\text { OAT10 }\end{array}$ & $\begin{array}{l}\text { Cymabay licensed } \\
\text { to Kowa }\end{array}$ & $\begin{array}{l}\text { http://www.cymabay.com/pipeline. } \\
\text { html, http://www.kowa.co.jp/eng/ } \\
\text { company/division/pharmaceutic/labo. } \\
\text { htm }\end{array}$ & $2 b$ & $\begin{array}{l}\text { Last study completed 2016, } \\
\text { (NCT01399008, last } \\
\text { updated September 2015) }\end{array}$ & $(270-272)$ \\
\hline URC-102 & & URAT1 & $\begin{array}{l}\text { Chugai/JW } \\
\text { Pharmaceuticals }\end{array}$ & $\begin{array}{l}\text { https://www.chugai-pharm.co.jp/ } \\
\text { english/ir/reports_downloads/ } \\
\text { pipeline.html http://www.cwp.co.kr/ } \\
\text { pharma/en/randd/develop.jsp }\end{array}$ & 2 & $\begin{array}{l}\text { Last study completed 2015, } \\
\text { (NCT02290210, last } \\
\text { updated March, 2017) }\end{array}$ & \\
\hline AC-201 & Diacerein & $\begin{array}{l}\text { interleukin-1 } \beta \\
(\mathrm{IL}-1 \beta) \text { modulator }\end{array}$ & TWi Biotechnology & $\begin{array}{l}\text { http://www.twibiotech.com/rAndD_ } \\
11\end{array}$ & $?$ & $\begin{array}{l}\text { Last study completed } 2016 \\
\text { (NCT02287818, last } \\
\text { updated April 2017) }\end{array}$ & \\
\hline Verinurad & $\begin{array}{l}\text { RDEA- } \\
3170\end{array}$ & URAT1i & AstraZeneca & $\begin{array}{l}\text { https://www.astrazeneca.com/our- } \\
\text { science/pipeline.html }\end{array}$ & 2 & $\begin{array}{l}\text { Ongoing trial } \\
\text { (NCT03118739-last } \\
\text { updated July 2017) }\end{array}$ & (273) \\
\hline
\end{tabular}

Inclusion in this table was based on evidence of trial activity on Clintrials. gov within the 2 years prior to compilation and listing on company websites. Other compounds may be in active development that do not meet this criteria.

$300 \mathrm{mg}$ allopurinol group and $-24.9 \%$ in the $300 \mathrm{mg}$ allopurinol $+0.6 \mathrm{mg}$ colchicine group.

The efficacy and tolerability of arhalofenate have been evaluated both as a monotherapy at doses of 600 and $800 \mathrm{mg}$ once daily and in combination with febuxostat 40 and $80 \mathrm{mg}$ (276).
The primary objectives of the study were to assess reduction in sUA with arhalofenate as a monotherapy and when combined with febuxostat as both absolute and percentage reductions from baseline, the percentage of patients achieving the target sUA of $<6,<5$, and $<4 \mathrm{mg} / \mathrm{dL}$, and the potential for interaction 
between the two compounds. Arhalofenate as a monotherapy showed a modest reduction in sUA of approximately 19$24 \%$. However, in combination with 40 or $80 \mathrm{mg}$ febuxostat all patients were reported to achieve the target sUA of $<6 \mathrm{mg} / \mathrm{dL}$. Additionally, more subjects ( 0 vs. $20 \%$ and 29 vs. $79 \%$ for 40 and $80 \mathrm{mg}$ of febuxostat vs. combination with $800 \mathrm{mg}$ arhalofenate) achieved the more stringent goal of $<4 \mathrm{mg} / \mathrm{dL}$. Combination with febuxostat did not markedly affect the pharmacokinetics of arhalofenate. Overall these results were an improvement over either arhalofenate or febuxostat monotherapies which were monitored as comparators.

Arhalofenate was recently licensed to Kowa Pharmaceuticals ${ }^{6}$ suggesting the compound may progress to Phase 3 trials and, if successful, could become the first compound to combine uratelowering and flare reduction in a single agent.

\section{AC-201 (Diacerein/Diacetylrhein)}

AC-201 (TWi biotechnology) is a small molecule IL-1 $\beta$ modulator that was originally developed for use in osteoarthritis. However, it has since been evaluated more broadly for metabolic indications including treatment of type 2 diabetes and gout flare prophylaxis. Indeed, AC-201 has been approved as diacerein for chronic rheumatic disease and is already in clinical use. However, clinical data suggested potential dual effects in reducing sUA levels through inhibition of reabsorption transporters in the kidney. This molecule is currently listed as being actively assessed in Phase 2 clinical development at $50 \mathrm{mg}$ dosage (including a controlled release formulation). A trial was carried out to determine the capability to reduce flares and time of onset to flares for patients who started on urate lowering therapies ${ }^{7}$ with the proportion of patients meeting the goal of $<6.0$ or $<5.0 \mathrm{mg} / \mathrm{dL}$ assessed over 16 weeks. Overall the possible dual action of reduction in flares combined with increases in urate excretion could prove beneficial relative to other emerging drugs in this area and represents a potential competitor to arhalofenate with a dual anti-inflammatory/sUA lowering profile. However, currently there are only limited data available for this compound in the public domain (226).

\section{RDEA3170 (verinurad)}

Further optimization of the RDEA594 (lesinurad) template culminated in the development of RDEA3170 (verinurad) which reportedly has a URAT1 $\mathrm{IC}_{50}$ of $25 \mathrm{nM}$ and is currently in Phase 2 clinical trials $(97,255,273)$. This is more potent than lesinurad which has been reported to have a URAT1 IC $_{50}$ of $3.4 \mu \mathrm{M}$. Verinurad completed a Phase I clinical trial, in Japanese patients with gout or with asymptomatic hyperuricemia, which was designed to demonstrate its urate lowering effects (94, 278). Doses ranging from 5 to $12.5 \mathrm{mg}$ per day were given and resulted in $>60 \%$ decrease in the mean sUA levels in patients. Phase 2 trials of verinurad in combination with either febuxostat or allopurinol were then initiated (279, 280).

\footnotetext{
${ }^{6}$ http://www.kowapharma.com/newsroom/pr-2017-01-03/

${ }^{7} \mathrm{https} / /$ clinicaltrials.gov/ct2/show/NCT02287818
}

\section{FYU-981}

FYU-981 (Fuji Yakuhin Co.) is in Phase 3 clinical trials for patients with hyperuricemia both with and without gout ${ }^{8}$ However, despite being in advanced clinical trials, very little appears to have been published about this compound to date.

\section{URC-102 (UR-1102)}

URC-102 (JW Pharmaceutical) has recently been through Phase 2 clinical trials to assess efficacy and safety in gout patients at $0.25 \mathrm{mg}$ to $2.0 \mathrm{mg}$ doses $^{9}$ Published studies on this compound showed selective inhibition of the URAT1 transporter (281). However, no clinical data for this compound has been reported.

\section{Selected Compounds Without Recent Clinical Progress}

In addition to the aforementioned compounds which appear to be still actively progressing in clinical trials, there are a number of recent compounds for which no recent clinical activity has been reported. These include alternative novel XO inhibitors such as LC350189 by LG Life Sciences for the management of hyperuricemia in gout patients (282). Also, alternative uricosuric compounds were progressed into clinical trials, such as the proposed re-purposing of tranilast, an antiinflammatory drug which has been used for many decades in Japan for bronchial asthma that had a secondary uricosuric effect. This uricosuric effect was later attributed to weak inhibition of GLUT9 in addition to URAT1, OAT4 and OAT10 (283). In addition, tranilast appears to inhibit a number of secretory urate transporters including NPT1, OAT1 and OAT3 which may also contribute to this effect to some extent. A novel dual XO and URAT1 inhibitor, PF-06743649, combined both inhibition of uric acid biosynthesis and increase urate excretion and was evaluated in partnership by Kissei Pharmaceuticals and Pfizer up to Phase 2 clinical trials for hyperuricemia and gout treatment, but was terminated due to emergent renal safety risks (284). Ulodesine (BCX4208) is also noteworthy as it represented a novel mode of action, outside of XO inhibitors, uricosuric and uricolytic agents. This is a potent purine nucleoside phosphorylase (PNP) inhibitor acting upstream of xanthine oxidase inhibitors $(285,286)$.

\section{CONCLUSIONS}

Asymptomatic hyperuricemia appears to be increasing in prevalence. High levels of circulating uric acid have been associated with the increased risk for developing gout and kidney stones. Indeed, gout is the most common form of inflammatory arthritis with well-studied epidemiology. The natural history of gout can be summarized as asymptomatic hyperuricemia, acute gouty arthritis, intercritical period and chronic tophaceous gout; with diagnosis based on both laboratory and radiological features. The role of genetic predisposition is becoming more evident and new insights into the pathophysiology of hyperuricemia and gouty arthritis (both acute and chronic) allow for an even better understanding of the disease.

\footnotetext{
${ }^{8}$ https://clinicaltrials.gov/ct2/show/NCT03006445

${ }^{9}$ https://clinicaltrials.gov/ct2/show/NCT02290210
} 
Gout is an eminently curable condition with approaches that include management of the inflammatory pain associated with flares, urate lowering therapies that address the underlying cause, as well as other approaches such as improved patient education. It has been suggested that clear visualization of treatment outcome could, in combination with improved patient education, help address the issue of poor patient compliance (287). If the treatment paradigm shifts further toward active management of hyperuricemia, we anticipate that patients will benefit from more facile methods for determining uric acid concentrations in biofluids which, together with increased availability of mobile applications (such as smart-device applications), has the potential to allow non-invasive self-assessment and subsequent disease management.

The associations between hyperuricemia and many comorbidities such as hypertension, cardiovascular disease, diabetes, metabolic syndrome, dyslipidemia, acute and chronic kidney disease are well recognized. However, the causal relationship between hyperuricemia and these co-morbidities is still a subject of debate. Recent years have witnessed many experimental, epidemiological (including Mendelian randomization studies) and clinical therapeutic interventional studies seeking to test the hypothesis that hyperuricemia plays a pathophysiological role in these disease entities, many of which are important public health challenges. These investigations have been limited by the lack of a standardized approach for definition of hyperuricemia, and by duration and/or size. Nonetheless, the results are interesting enough to warrant further investigation with larger randomized controlled trials to establish the role of uric acid as a promising target for novel

\section{REFERENCES}

1. Brook RA, Forsythe A, Smeeding JE, Lawrence Edwards N. Chronic gout: epidemiology, disease progression, treatment and disease burden. Curr Med Res Opin. (2010) 26:2813-21. doi: 10.1185/03007995.2010.533647

2. Burns CM, Wortmann RL. Latest evidence on gout management: what the clinician needs to know. Ther Adv Chronic Dis. (2012) 3:271-286. doi: $10.1177 / 2040622312462056$

3. Kuo CF, Grainge MJ, Zhang W, Doherty M. Global epidemiology of gout: prevalence, incidence and risk factors. Nat Rev Rheumatol. (2015) 11:649-62. doi: 10.1038/nrrheum.2015.91

4. Zhu Y, Pandya BJ, Choi H.K. Prevalence of gout and hyperuricemia in the US general population: the National Health and Nutrition ExaminationSurvey 2007-2008. Arthritis Rheum. (2011) 63:3136-41. doi: 10.1002/art.30520

5. Zhu Y, Pandya BJ, Choi H.K. Comorbidities of gout and hyperuricemia in the US general population:NHANES 2007-2008. Am J Med. (2012) 125:679-87 e671. doi: 10.1016/j.amjmed.2011.09.033

6. Robinson PC, Taylor WJ, Merriman T.R. Systematic review of the prevalence of gout and hyperuricaemia in Australia. Intern Med J. (2012) 42:997-1007. doi: 10.1111/j.1445-5994.2012.02794.x

7. Chuang SY, Lee SC, Hsieh YT, Pan W.H. Trends in hyperuricemia and gout prevalence: Nutrition and Health Survey in Taiwanfrom 1993-1996 to 2005-2008. Asia Pac J Clin Nutr. (2011) 20:301-8.

8. Juraschek SP, Miller ER III, Gelber AC. Body mass index, obesity, and prevalent gout in the United Statesin 1988-1994 and 2007-2010. Arthritis Care Res. (2013) 65:127-32. doi: 10.1002/acr.21791 therapeutic interventions in the management of kidney and cardio-metabolic disease. Indeed, there have been notable efforts to standardize medical approaches regarding outcome measures, staging and management but there are still some notable gaps.

For example, despite ongoing efforts to educate practitioners on the appropriate titration of allopurinol (which is still often used as the therapy of choice), prescribed doses are typically around $300 \mathrm{mg}$ in clinical practice which in turn leads to suboptimal outcomes. However, the increasing number of therapeutic options may help address this issue by removing requirements for dose titration, as is the case with newer $\mathrm{XO}$ inhibitors, or using combinations of XO inhibitors and uricosurics in patients who do not achieve sUA goals with $\mathrm{XO}$ inhibitors alone. Finally, further agents in development will likely benefit from our better understanding of pathophysiology. Taken together, there is genuine potential for further drug development to lead to better management in patients with hyperuricemia, gout and associated conditions in the coming years.

\section{AUTHOR CONTRIBUTIONS}

$\mathrm{CB}$ conceived the manuscript. $\mathrm{CB}, \mathrm{RS}, \mathrm{AP}, \mathrm{CV}, \mathrm{PL}$ and $\mathrm{RG}$ collected and reviewed the literature and wrote the main body of the manuscript. PL and PD critically reviewed the manuscript. All authors approved the final version of the manuscript.

\section{ACKNOWLEDGMENTS}

We acknowledge the support of former colleagues who were members of the Pfizer Neusentis URAT1 team for relevant helpful discussions.
9. Merriman TR, Dalbeth N, Johnson R.J. Sugar-sweetened beverages, urate, gout and genetic interaction. Pac Health Dialog. (2014) 20:31-8.

10. Holland R, McGill NW. Comprehensive dietary education in treated gout patients does not further improve serum urate. Intern Med J. (2015) 45:18994. doi: 10.1111/imj.12661

11. Kim SY, Guevara JP, Kim KM, Choi HK, Heitjan DF, Albert DA. Hyperuricemia and risk of stroke: a systematic review and meta-analysis. Arthritis Rheum. (2009) 61:885-92. doi: 10.1002/art.24612

12. Kim SY, Guevara JP, Kim KM, Choi HK, Heitjan DF, Albert DA. Hyperuricemia and coronary heart disease: a systematic review and meta-analysis. Arthritis Care Res. (2010) 62:170-80. doi: 10.1002/acr. 20065

13. Li L, Yang C, Zhao Y, Zeng X, Liu F, Fu P. Is hyperuricemia an independent risk factor for new-onset chronic kidney disease?: A systematic review and meta-analysis based on observational cohort studies. BMC Nephrol. (2014) 15:122. doi: 10.1186/1471-2369-15-122

14. Li M, Hou W, Zhang X, Hu L, Tang Z. Hyperuricemia and risk of stroke: a systematic review and meta-analysis of prospective studies. Atherosclerosis (2014) 232:265-70. doi: 10.1016/j.atherosclerosis.2013.11.051

15. Wang J, Qin T, Chen J, Li Y, Wang L, Huang H, et al. Hyperuricemia and risk of incident hypertension: a systematic review and metaanalysis of observational studies. PLoS ONE (2014) 9:e114259. doi: 10.1371/journal.pone.0114259

16. Kim S, Chang Y, Yun KE, Jung HS, Lee SJ, Shin H, et al. Development of nephrolithiasis in asymptomatic hyperuricemia: a cohort study. Am J Kidney Dis. (2017) 70:173-81. doi: 10.1053/j.ajkd.2017.01.053 
17. Stamp L, Dalbeth N. Urate-lowering therapy for asymptomatic hyperuricaemia: a need for caution. Semin Arthritis Rheum. (2017) 46:457-64. doi: 10.1016/j.semarthrit.2016.07.015

18. Richette P, Doherty M, Pascual E, Barskova V, Becce F, CastanedaSanabria J, et al. 2016 updated EULAR evidence-based recommendations for the management of gout. Ann Rheum Dis. (2017) 76:29-42. doi: 10.1136/annrheumdis-2016-209707

19. Chong DP. Theoretical study of uric acid and its ions in aqueous solution. $J$ Theor Comput Sci. (2013) 1:104. doi: 10.4172/jtco.1000104

20. Desideri G, Castaldo G, Lombardi A, Mussap M, Testa A, Pontremoli R, et al. Is it time to revise the normal range of serum uric acid levels? Eur Rev Med Pharmacol Sci. (2014) 18:1295-306.

21. Kratzer JT, Lanaspa MA, Murphy MN, Cicerchi C, Graves CL, Tipton PA, et al. Evolutionary history and metabolic insights of ancient mammalian uricases. Proc Natl Acad Sci USA. (2014) 111:3763-8. doi: 10.1073/pnas.1320393111

22. Gao X, O’Reilly EJ, Schwarzschild MA, Ascherio A. Prospective study of plasma urate and risk of Parkinson disease in men and women.Neurology (2016) 86:520-6. doi: 10.1212/WNL.0000000000002351

23. Paganoni S, Schwarzschild M.A. Urate as a Marker of Risk and Progression of Neurodegenerative Disease.Neurotherapeutics (2017) 14:14853. doi: 10.1007/s13311-016-0497-4

24. Wen M, Zhou B, Chen YH, Ma ZL, Gou Y, Zhang CL, et al. Serum uric acid levels in patients with Parkinson's disease: a meta-analysis. PLoS ONE (2017) 12:e0173731. doi: 10.1371/journal.pone.0173731

25. Loffler W, Grobner W, Medina R, Zollner N. Influence of dietary purines on pool size, turnover, and excretion of uric acid during balance conditions. Isotope studiesusing 15N-uric acid. Res Exp Med. (1982) 181:113-23. doi: 10.1007/BF01852188

26. Maiuolo J, Oppedisano F, Gratteri S, Muscoli C, Mollace V. Regulation of uric acid metabolism and excretion. Int J Cardiol. (2016) 213:8-14. doi: 10.1016/j.ijcard.2015.08.109

27. Johnson RJ, Nakagawa T, Sanchez-Lozada LG, Shafiu M, Sundaram S, Le M, et al. Sugar, uric acid, and the etiology of diabetes and obesity. Diabetes (2013) 62:3307-15. doi: 10.2337/db12-1814

28. Thottam GE, Krasnokutsky S, Pillinger M.H. Gout and metabolic syndrome: a tangled web. Curr Rheumatol Rep. (2017) 19:60. doi: 10.1007/s11926-017-0688-y

29. Lanaspa MA, Sanchez-Lozada LG, Cicerchi C, Li N, Roncal-Jimenez CA, Ishimoto $\mathrm{T}$, et al. Uric acid stimulates fructokinase and accelerates fructose metabolism in the development of fatty liver. PLoS ONE (2012) 7:e47948. doi: 10.1371/journal.pone.0047948

30. Chaudhary K, Malhotra K, Sowers J, Aroor A. Uric Acid - key ingredient in the recipe for cardiorenal metabolic syndrome. Cardiorenal Med. (2013) 3:208-20. doi: 10.1159/000355405

31. Pacher P, Nivorozhkin A, Szabo C. Therapeutic effects of xanthine oxidase inhibitors: renaissance half a century after the discovery of allopurinol. Pharmacol Rev. (2006) 58:87-114. doi: 10.1124/pr.58.1.6

32. Sorensen LB. Role of the intestinal tract in the elimination of uric acid. Arthritis Rheum. (1965) 8:694-706. doi: 10.1002/art.1780080429

33. Hyndman D, Liu S, Miner J.N. Urate handling in the human body. Curr Rheumatol Rep. (2016) 18:34. doi: 10.1007/s11926-016-0587-7

34. Rieselbach RE, Sorensen LB, Shelp WD, Steele TH. Diminished renal urate secretion per nephron as a basis for primary gout. Ann Intern Med. (1970) 73:359-66. doi: 10.7326/0003-481973-3-359

35. Garcia Puig J, Mateos Anton F, Lopez Jimenez M, Conthe Gutierrez P. Renal handling of uric acid in gout: impaired tubular transport of urate not dependent on serum urate levels.Metabolism (1986) 35:1147-53. doi: 10.1016/0026-0495(86)90028-4

36. Mandal AK, Mount DB. The molecular physiology of uric acid homeostasis. Annu Rev Physiol. (2015) 77:323-45. doi: 10.1146/annurev-physiol-021113170343

37. Hediger MA, Johnson RJ, Miyazaki H, Endou H. Molecular physiology of urate transport. Physiology (2005) 20:125-33. doi: 10.1152/physiol.00039.2004

38. Wright AF, Rudan I, Hastie ND, Campbell H. A 'complexity' of urate transporters. Kidney Int. (2010) 78:446-52. doi: 10.1038/ki.2010.206
39. Enomoto A, Kimura H, Chairoungdua A, Shigeta Y, Jutabha P, Cha SH, et al. Molecular identification of a renal urate anion exchanger that regulates blood urate levels. Nature (2002) 417:447-52. doi: 10.1038/nature742

40. Ohtsu N, Anzai N, Fukutomi T, Kimura T, Sakurai H, Endou H. [Human renal urate transpoter URAT1 mediates the transport of salicylate]. Nihon Jinzo Gakkai Shi (2010) 52:499-504.

41. Miura D, Anzai N, Jutabha P, Chanluang S, He X, Fukutomi T, et al. Human urate transporter 1 (hURAT1) mediates the transport of orotate. J Physiol Sci. (2011) 61:253-7. doi: 10.1007/s12576-011-0136-0

42. Lu Y, Nakanishi T, Tamai I. Functional cooperation of SMCTs and URAT1 for renal reabsorption transport of urate. Drug Metab Pharmacokinet. (2013) 28:153-8. doi: 10.2133/dmpk.DMPK-12-RG-070

43. Otani N, Ouchi M, Hayashi K, Jutabha P, Anzai N. Roles of organic anion transporters (OATs) in renal proximal tubules and their localization. Anat Sci Int. (2017) 92:200-6. doi: 10.1007/s12565-016-0369-3

44. Ichida K, Hosoyamada M, Kamatani N, Kamitsuji S, Hisatome I, Shibasaki T, et al. Age and origin of the G774A mutation in SLC22A12 causing renal hypouricemia in Japanese. Clin Genet. (2008) 74:243-51. doi: 10.1111/j.1399-0004.2008.01021.x

45. Li C, Li Z, Liu S, Wang C, Han L, Cui L, et al. Genome-wide association analysis identifies three new risk loci for gout arthritis in Han Chinese. Nat Commun. (2015) 6:7041. doi: 10.1038/ncomms8041

46. Kolz M, Johnson T, Sanna S, Teumer A, Vitart V, Perola M, et al. Metaanalysis of 28,141 individuals identifies common variants within five new loci that influence uric acid concentrations. PLoS Genet. (2009) 5:e1000504. doi: 10.1371/journal.pgen.1000504

47. Kamatani Y, Matsuda K, Okada Y, Kubo M, Hosono N, Daigo Y, et al. Genome-wide association study of hematological and biochemical traits in a Japanese population. Nat Genet. (2010) 42:210-5. doi: 10.1038/ng.531

48. Yang Q, Kottgen A, Dehghan A, Smith AV, Glazer NL, Chen MH, et al. Multiple genetic loci influence serum urate levels and their relationship with gout and cardiovascular disease risk factors. Circ Cardiovasc Genet. (2010) 3:523-30. doi: 10.1161/CIRCGENETICS.109.934455

49. Sulem P, Gudbjartsson DF, Walters GB, Helgadottir HT, Helgason A, Gudjonsson SA, et al. Identification of low-frequency variants associated with gout and serum uric acid levels. Nat Genet. (2011) 43:1127-30. doi: 10.1038/ng.972

50. Karns R, Zhang G, Sun G, Rao Indugula S, Cheng H, Havas-Augustin D, et al. Genome-wide association of serum uric acid concentration: replication of sequence variants in an island population of the Adriatic coast of Croatia. Ann Hum Genet. (2012) 76:121-7. doi: 10.1111/j.1469-1809.2011.00698.x

51. Kottgen A, Albrecht E, Teumer A, Vitart V, Krumsiek J, Hundertmark $\mathrm{C}$, et al. Genome-wide association analyses identify 18 new loci associated with serum urate concentrations. Nat Genet. (2013) 45:145-54. doi: 10.1038/ng.2500

52. Yang B, Mo Z, Wu C, Yang H, Yang X, He Y, et al. A genome-wide association study identifies common variants influencing serum uric acid concentrations in a Chinese population. BMC Med Genomics (2014) 7:10. doi: 10.1186/1755-8794-7-10

53. Dong Z, Guo S, Yang Y, Wu J, Guan M, Zou H, et al. Association between ABCG2 Q141K polymorphism and gout risk affected by ethnicity and gender: a systematic review and meta-analysis. Int J Rheum Dis. (2015) 18:382-91. doi: 10.1111/1756-185X.12519

54. Huffman JE, Albrecht E, Teumer A, Mangino M, Kapur K, Johnson $\mathrm{T}$, et al. Modulation of genetic associations with serum urate levels by body-mass-index in humans. PLoS ONE (2015) 10:e0119752. doi: 10.1371/journal.pone.0119752

55. Giri AK, Banerjee P, Chakraborty S, Kauser Y, Undru A, Roy S, et al. Genome wide association study of uric acid in Indian population and interaction of identified variants with Type 2 diabetes. Sci Rep. (2016) 6:21440. doi: 10.1038/srep21440

56. Matsuo H, Yamamoto K, Nakaoka H, Nakayama A, Sakiyama M, Chiba T, et al. Genome-wide association study of clinically defined gout identifies multiple risk loci and its association with clinical subtypes. Ann Rheum Dis. (2016) 75:652-9. doi: 10.1136/annrheumdis-2014-206191

57. Li M, Li Q, Li CG, Guo M, Xu JM, Tang YY, et al. Genetic polymorphisms in the PDZK1 gene and susceptibility to gout in male Han Chinese: a case-control study. Int J Clin Exp Med. (2015) 8:13911-8. 
58. Nakayama A, Nakaoka H, Yamamoto K, Sakiyama M, Shaukat A, Toyoda Y, et al. GWAS of clinically defined gout and subtypes identifies multiple susceptibility loci that include urate transporter genes. Ann Rheum Dis. (2017) 76:869-77. doi: 10.1136/annrheumdis-2016-209632

59. Li S, Sanna S, Maschio A, Busonero F, Usala G, Mulas A, et al. The GLUT9 gene is associated with serum uric acid levels in Sardinia and Chianti cohorts. PLoS Genet. (2007) 3:e194. doi: 10.1371/journal.pgen.00 30194

60. Anzai N, Ichida K, Jutabha P, Kimura $\mathrm{T}$, Babu E, Jin CJ, et al. Plasma urate level is directly regulated by a voltage-driven urate efflux transporter URATv1 (SLC2A9) in humans. J Biol Chem. (2008) 283:26834-8. doi: 10.1074/jbc.C800156200

61. Dehghan A, van Hoek M, Sijbrands EJ, Hofman A, Witteman JC. High serum uric acid as a novel risk factor fortype 2 diabetes. Diabetes Care (2008) 31:361-2. doi: 10.2337/dc07-1276

62. Doring A, Gieger C, Mehta D, Gohlke H, Prokisch H, Coassin S, et al. SLC2A9 influences uric acid concentrations with pronounced sex-specific effects. Nat Genet. (2008) 40:430-6. doi: 10.1038/ng.107

63. Matsuo H, Chiba T, Nagamori S, Nakayama A, Domoto H, Phetdee $\mathrm{K}$, et al. Mutations in glucose transporter 9 gene SLC2A9 cause renal hypouricemia. Am J Hum Genet. (2008) 83:744-51. doi: 10.1016/j.ajhg.2008. 11.001

64. McArdle PF, Parsa A, Chang YP, Weir MR, O'Connell JR, Mitchell BD, et al. Association of a common nonsynonymous variant in GLUT9 with serum uric acid levels in old order amish. Arthritis Rheum. (2008) 58:2874-81. doi: 10.1002/art.23752

65. Vitart V, Rudan I, Hayward C, Gray NK, Floyd J, Palmer CN, et al. SLC2A9 is a newly identified urate transporter influencing serum urate concentration, urate excretion and gout. Nat Genet. (2008) 40:437-42. doi: 10.1038/ ng.106

66. Wallace C, Newhouse SJ, Braund P, Zhang F, Tobin M, Falchi M, et al. Genome-wide association study identifies genes for biomarkers of cardiovascular disease: serum urate and dyslipidemia. Am J Hum Genet. (2008) 82:139-49. doi: 10.1016/j.ajhg.2007.11.001

67. Bahat H, Dinour D, Ganon L, Feldman L, Holtzman EJ, Goldman M. Non-urate transporter 1-related renal hypouricemia and acute renal failure in an Israeli-Arab family. Pediatr Nephrol. (2009) 24:999-1003. doi: 10.1007/s00467-008-1093-6

68. Dinour D, Gray NK, Campbell S, Shu X, Sawyer L, Richardson $\mathrm{W}$, et al. Homozygous SLC2A9 mutations cause severe renal hypouricemia. J Am Soc Nephrol. (2010) 21:64-72. doi: 10.1681/ASN.20090 40406

69. Charles BA, Shriner D, Doumatey A, Chen G, Zhou J, Huang H, et al. A genome-wide association study of serum uric acid in African Americans. BMC Med Genomics (2011) 4:17. doi: 10.1186/1755-8794-4-17

70. Hamajima N, Okada R, Kawai S, Hishida A, Morita E, Yin G, et al. Significant association of serum uric acid levels with SLC2A9 rs11722228 among a Japanese population. Mol Genet Metab. (2011) 103:378-82. doi: 10.1016/j.ymgme.2011.04.001

71. Kawamura Y, Matsuo H, Chiba T, Nagamori S, Nakayama A, Inoue $\mathrm{H}$, et al. Pathogenic GLUT9 mutations causing renal hypouricemia type 2 (RHUC2). Nucleosides Nucleotides Nucleic Acids (2011) 30:1105-11. doi: 10.1080/15257770.2011.623685

72. Shima Y, Nozu K, Nozu Y, Togawa H, Kaito H, Matsuo M, et al. Recurrent EIARF and PRES with severe renal hypouricemia by compound heterozygous SLC2A9 mutation. Pediatrics (2011) 127:e1621-5. doi: 10.1542/peds.2010-2592

73. Nakanishi T, Ohya K, Shimada S, Anzai N, Tamai I. Functional cooperation of URAT1 (SLC22A12) and URATv1 (SLC2A9) in renal reabsorption of urate. Nephrol Dial Transplant. (2013) 28:603-11. doi: 10.1093/ndt/gfs574

74. Voruganti VS, Kent JW Jr, Debnath S, Cole SA, Haack K, Goring HH, et al. Genome-wide association analysis confirms and extends the association of SLC2A9 with serum uric acid levels to Mexican Americans. Front Genet. (2013) 4:279. doi: 10.3389/fgene.2013.00279

75. Chiba T, Matsuo H, Nagamori S, Nakayama A, Kawamura Y, Shimizu S, et al. Identification of a hypouricemia patient with SLC2A9 R380W, a pathogenic mutation for renal hypouricemia type 2. Nucleosides Nucleotides Nucleic Acids (2014) 33:261-5. doi: 10.1080/15257770.2013.857781
76. Voruganti VS, Franceschini N, Haack K, Laston S, MacCluer JW, Umans JG, et al. Replication of the effect of SLC2A9 genetic variation on serum uric acid levels in American Indians. Eur J Hum Genet. (2014) 22:938-43. doi: 10.1038/ejhg.2013.264

77. Androvitsanea A, Stylianou K, Maragkaki E, Tzanakakis M, Stratakis $\mathrm{S}$, Petrakis I, et al. Vanishing urate, acute kidney injury episodes and a homozygous SLC2A9 mutation. Int Urol Nephrol. (2015) 47:1035-6. doi: 10.1007/s11255-015-1005-1

78. Nagy R, Boutin TS, Marten J, Huffman JE, Kerr SM, Campbell A, et al. Exploration of haplotype research consortium imputation for genome-wide association studies in 20,032 Generation Scotland participants. Genome Med. (2017) 9:23. doi: 10.1186/s13073-017-0414-4

79. Torres RJ, de Miguel E, Bailen R, Banegas JR, Puig JG. Tubular urate transporter gene polymorphisms differentiate patients with gout who have normal and decreased urinary uric acid excretion. J Rheumatol. (2014) 41:1863-70. doi: 10.3899/jrheum.140126

80. Lytvyn Y, Skrtic M, Yang GK, Yip PM, Perkins BA, Cherney DZ. Glycosuriamediated urinary uric acid excretion in patients with uncomplicated type 1 diabetes mellitus. Am J Physiol Renal Physiol. (2015) 308:F77-83. doi: 10.1152/ajprenal.00555.2014

81. Ma L, Wei L, Chen H, Zhang Z, Yu Q, Ji Z, et al. Influence of urate-lowering therapies on renal handling of uric acid. Clin Rheumatol. (2016) 35:133-41. doi: 10.1007/s10067-014-2806-9

82. Jutabha P, Anzai N, Kitamura K, Taniguchi A, Kaneko S, Yan K, et al. Human sodium phosphate transporter 4 (hNPT4/SLC17A3) as a common renal secretory pathway for drugs and urate. J Biol Chem. (2010) 285:35123-32. doi: 10.1074/jbc.M110.121301

83. Tanaka M, Itoh K, Matsushita K, Matsushita K, Wakita N, Adachi M, et al. Two male siblings with hereditary renal hypouricemia and exerciseinduced ARF. Am J Kidney Dis. (2003) 42:1287-92. doi: 10.1053/j.ajkd.2003. 08.032

84. Wakida N, Tuyen DG, Adachi M, Miyoshi T, Nonoguchi H, Oka T, et al. Mutations in human urate transporter 1 gene in presecretory reabsorption defect type of familial renal hypouricemia. J Clin Endocrinol Metab. (2005) 90:2169-74. doi: 10.1210/jc.2004-1111

85. Dinour D, Bahn A, Ganon L, Ron R, Geifman-Holtzman O, Knecht A, et al. URAT1 mutations cause renal hypouricemia type 1 in Iraqi Jews. Nephrol Dial Transplant. (2011) 26:2175-81. doi: 10.1093/ndt/gfq722

86. Ichida K, Amaya Y, Kamatani N, Nishino T, Hosoya T, Sakai O. Identification of two mutations in human xanthine dehydrogenase gene responsible for classical type I xanthinuria. J Clin Invest. (1997) 99:2391-7. doi: 10.1172/JCI119421

87. Sakamoto N, Yamamoto T, Moriwaki Y, Teranishi T, Toyoda M, Onishi $\mathrm{Y}$, et al. Identification of a new point mutation in the human xanthine dehydrogenase gene responsible for a case of classical type I xanthinuria. Hum Mol Genet. (2001) 108:279-83.

88. Tin A, Woodward OM, Kao WH, Liu CT, Lu X, Nalls MA, et al. Genome-wide association study for serum urate concentrations and gout among African Americans identifies genomic risk loci and a novel URAT1 loss-of-function allele. Hum Mol Genet. (2011) 20:4056-68. doi: 10.1093/hmg/ddr307

89. Hosoyamada M, Takiue Y, Shibasaki T, Saito H. The effect of testosterone upon the urate reabsorptive transport system in mouse kidney. Nucleosides Nucleotides Nucleic Acids (2010) 29:574-79. doi: 10.1080/15257770.2010.494651

90. Takiue Y, Hosoyamada M, Kimura M, Saito H. The effect of female hormones upon urate transport systems in the mouse kidney. Nucleosides Nucleotides Nucleic Acids (2011) 30:113-9. doi: 10.1080/15257770.2010.5 51645

91. Anzai N, Miyazaki H, Noshiro R, Khamdang S, Chairoungdua A, Shin HJ, et al. The multivalent PDZ domain-containing protein PDZK1 regulates transport activity of renal urate-anion exchanger URAT1 via its $\mathrm{C}$ terminus. J Biol Chem. (2004) 279:45942-50. doi: 10.1074/jbc.M406724200

92. Raychaudhuri S, Plenge RM, Rossin EJ, Ng AC, International Schizophrenia Consortium, Purcell SM, et al. Identifying relationships among genomic disease regions: predicting genes at pathogenic SNP associations and rare deletions. PLoS Genet. (2009) 5:e1000534. doi: 10.1371/journal.pgen.10 00534 
93. Shin HJ, Takeda M, Enomoto A, Fujimura M, Miyazaki H, Anzai N, et al. Interactions of urate transporter URAT1 in human kidney with uricosuric drugs. Nephrology (2011) 16:156-62. doi: 10.1111/j.1440-1797.2010.01368.x

94. Wempe MF, Lightner JW, Miller B, Iwen TJ, Rice PJ, Wakui S, et al. Potent human uric acid transporter 1 inhibitors: in vitro and in vivo metabolism and pharmacokinetic studies. Drug Des Devel Ther. (2012) 6:323-39. doi: 10.2147/DDDT.S35805

95. Miner J, Tan PK, Hyndman D, Liu S, Iverson C, Nanavati P, et al. Lesinurad, a novel, oral compound for gout, acts to decrease serum uric acid through inhibition of urate transporters in the kidney. Arthritis Res Ther. (2016) 18:214. doi: 10.1186/s13075-016-1107-x

96. Pike A, Storer RI, Owen RM, Armstrong E, Benn CL, Bictash $\mathrm{M}$, et al. The design, synthesis and evaluation of low molecular weight acidic sulfonamides as URAT1 inhibitors for the treatment of gout. MedChemComm (2016) 7:1572-9. doi: 10.1039/C6MD0 0191B

97. Storer RI, Owen RM, Pike A, Benn CL, Armstrong E, Blakemore DC, et al. The discovery and evaluation of diaryl ether heterocyclic sulfonamides as URAT1 inhibitors for the treatment of gout. MedChemComm (2016) 7:1587-95. doi: 10.1039/C6MD00190D

98. Tan PK, Liu S, Gunic E, Miner JN. Discovery and characterization of verinurad, a potent and specific inhibitor of URAT1 for the treatment of hyperuricemia and gout. Sci Rep. (2017) 7:665. doi: 10.1038/s41598-017-00706-7

99. Ichida K, Hosoyamada M, Hisatome I, Enomoto A, Hikita M, Endou H, et al. Clinical and molecular analysis of patients with renal hypouricemia in Japaninfluence of URAT1 gene on urinary urate excretion. J Am Soc Nephrol. (2004) 15:164-73. doi: 10.1097/01.ASN.0000105320.04395.D0

100. Anzai N, Jutabha P, Amonpatumrat-Takahashi S, Sakurai H. Recent advances in renal urate transport: characterization of candidate transporters indicated by genome-wide association studies. Clin Exp Nephrol. (2012) 16:89-95. doi: 10.1007/s10157-011-0532-z

101. Preitner F, Bonny O, Laverriere A, Rotman S, Firsov D, Da Costa A, et al. Glut9 is a major regulator of urate homeostasis and its genetic inactivation induces hyperuricosuria and urate nephropathy. Proc Natl Acad Sci USA. (2009) 106:15501-6. doi: 10.1073/pnas.0904411106

102. Dalbeth N, House ME, Gamble GD, Horne A, Pool B, Purvis L, et al. Population-specific influence of SLC2A9 genotype on the acute hyperuricaemic response to a fructose load. Ann Rheum Dis. (2013) 72:186873. doi: 10.1136/annrheumdis-2012-202732

103. Testa A, Mallamaci F, Spoto B, Pisano A, Sanguedolce MC, Tripepi $\mathrm{G}$, et al. Association of a polymorphism in a gene encoding a urate transporter with CKD progression. Clin J Am Soc Nephrol. (2014) 9:1059-65. doi: 10.2215/CJN.11041013

104. Doblado M, Moley KH. Facilitative glucose transporter 9, a unique hexose and urate transporter. Am J Physiol Endocrinol Metab. (2009) 297:E831-5. doi: 10.1152/ajpendo.00296.2009

105. Witkowska K, Smith KM, Yao SY, Ng AM, O’Neill D, Karpinski E, et al. Human SLC2A9a and SLC2A9b isoforms mediate electrogenic transport of urate with different characteristics in the presence of hexoses. Am J Physiol Renal Physiol. (2012) 303:F527-39. doi: 10.1152/ajprenal.00134.2012

106. Chino Y, Samukawa Y, Sakai S, Nakai Y, Yamaguchi J, Nakanishi T, et al. SGLT2 inhibitor lowers serum uric acid through alteration of uric acid transport activity in renal tubule by increased glycosuria. Biopharm Drug Dispos. (2014) 35:391-404. doi: 10.1002/bdd.1909

107. Davies MJ, Trujillo A, Vijapurkar U, Damaraju CV, Meininger G. Effect of canagliflozin on serum uric acid in patients with type 2 diabetes mellitus. Diabetes Obes Metab. (2015) 17:426-9. doi: 10.1111/dom.12439

108. Wang Y, Hu X, Liu X, Wang Z. An overview of the effect of sodium glucose cotransporter 2 inhibitor monotherapy on glycemic and other clinical laboratory parameters in type 2 diabetes patients. Ther Clin Risk Manag. (2016) 12:1113-31. doi: 10.2147/TCRM.S112236

109. Zhao Y, Xu L, Tian D, Xia P, Zheng H, Wang L, et al. Effects of sodiumglucose co-transporter 2 (SGLT2) inhibitors on serum uric acid level: a meta-analysis of randomized controlled trials. Diabetes Obes Metab. (2018) 20:458-62. doi: 10.1111/dom.13101

110. Sakiyama M, Matsuo H, Shimizu S, Nakashima H, Nakayama A, Chiba T, et al. A common variant of organic anion transporter 4 (OAT4/SLC22A11) gene is associated with renal underexcretion type gout. Drug Metab Pharmacokinet. (2014) 29:208-10. doi: 10.2133/dmpk.DMPK-13-NT-070

111. Ichida K, Matsuo H, Takada T, Nakayama A, Murakami K, Shimizu T, et al. Decreased extra-renal urate excretion is a common cause of hyperuricemia. Nat Commun. (2012) 3:764. doi: 10.1038/ncomms1756

112. Cleophas MC, Joosten LA, Stamp LK, Dalbeth N, Woodward OM, Merriman TR. ABCG2 polymorphisms in gout: insights into disease susceptibility and treatment approaches. Pharmgenomics Pers Med. (2017) 10:129-42. doi: 10.2147/PGPM.S105854

113. Takada T, Ichida K, Matsuo H, Nakayama A, Murakami K, Yamanashi Y, et al. ABCG2 dysfunction increases serum uric acid by decreased intestinal urate excretion. Nucleosides Nucleotides Nucleic Acids (2014) 33:275-81. doi: 10.1080/15257770.2013.854902

114. Iharada M, Miyaji T, Fujimoto T, Hiasa M, Anzai N, Omote H, et al. Type 1 sodium-dependent phosphate transporter (SLC17A1 Protein) is a $\mathrm{Cl}(-)$-dependent urate exporter. J Biol Chem. (2010) 285:26107-13. doi: 10.1074/jbc.M110.122721

115. Jutabha P, Anzai N, Wempe MF, Wakui S, Endou H, Sakurai H. Apical voltage-driven urate efflux transporter NPT4 in renal proximal tubule. Nucleosides Nucleotides Nucleic Acids (2011) 30:1302-11. doi: 10.1080/15257770.2011.616564

116. Rebane EN, Orlov Yu N, Kazbekov EN, Lyubimov Y, Bulat MN. The mechanism of coupling of the organic anion exchange to $\mathrm{Na}(+)$ dicarboxylate symport in basolateral membrane vesicles. Membr Cell Biol. (1998) 12:51-6.

117. Bakhiya A, Bahn A, Burckhardt G, Wolff N. Human organic anion transporter 3 (hOAT3) can operate as an exchanger and mediate secretory urate flux. Cell Physiol Biochem. (2003) 13:249-56. doi: 10.1159/0000 74539

118. Merriman TR. An update on the genetic architecture of hyperuricemia and gout. Arthritis Res Ther. (2015) 17:98. doi: 10.1186/s13075-015-0609-2

119. DeBoer MD, Gurka MJ. Low sensitivity for the metabolic syndrome to detect uric acid elevations in females and non-Hispanic-black male adolescents: an analysis of NHANES 1999-2006. Atherosclerosis (2012) 220:575-80. doi: 10.1016/j.atherosclerosis.2011.11.033

120. McAdams-DeMarco MA, Maynard JW, Baer AN, Kao LW, Kottgen A, Coresh J. A urate gene-by-diuretic interaction and gout risk in participants with hypertension: results from the ARIC study. Ann Rheum Dis. (2013) 72:701-6. doi: 10.1136/annrheumdis-2011-201186

121. Whitfield JB, Martin NG. Inheritance and alcohol as factors influencing plasma uric acid levels. Acta Genet Med Gemellol. (1983) 32:117-26. doi: 10.1017/S0001566000006401

122. Nath SD, Voruganti VS, Arar NH, Thameem F, Lopez-Alvarenga JC, Bauer $\mathrm{R}$, et al. Genome scan for determinants of serum uric acid variability. J Am Soc Nephrol. (2007) 18:3156-63. doi: 10.1681/ASN.2007040426

123. Emmerson BT, Nagel SL, Duffy DL, Martin NG. Genetic control of the renal clearance of urate: a study of twins. Ann Rheum Dis. (1992) 51:375-7. doi: 10.1136/ard.51.3.375

124. Wilk JB, Djousse L, Borecki I, Atwood LD, Hunt SC, Rich SS, et al. Segregation analysis of serum uric acid in the NHLBI Family Heart Study. Hum Genet. (2000) 106:355-9. doi: 10.1007/s004390051050

125. Esparza Martin N, Garcia Nieto V. Hypouricemia and tubular transport of uric acid.Nefrologia (2011) 31:44-50. doi: 10.3265/Nefrologia.pre2010.Oct. 10588

126. Kuwabara M, Niwa K, Ohtahara A, Hamada T, Miyazaki S, Mizuta E, et al. Prevalence and complications of hypouricemia in a general population: A large-scale cross-sectional study in Japan. PLoS ONE (2017d) 12:e0176055. doi: 10.1371/journal.pone.0176055

127. Levartovsky D, Lagziel A, Sperling O, Liberman U, Yaron M, Hosoya $\mathrm{T}$, et al. $\mathrm{XDH}$ gene mutation is the underlying cause of classical xanthinuria: a second report. Kidney Int. (2000) 57:2215-20. doi: 10.1046/j.1523-1755.2000.00082.x

128. Sebesta I. Genetic disorders resulting in hyper- or hypouricemia. $A d v$ Chronic Kidney Dis. (2012) 19:398-403. doi: 10.1053/j.ackd.2012.06.002

129. Kaito H, Ishimori S, Nozu K, Shima Y, Nakanishi K, Yoshikawa N, et al. Molecular background of urate transporter genes in patients with exercise-induced acute kidney injury. Am J Nephrol. (2013) 38:316-20. doi: 10.1159/000355430 
130. Wakasugi M, Kazama JJ, Narita I, Konta T, Fujimoto S, Iseki K, et al. Association between hypouricemia and reduced kidney function: a crosssectional population-based study in Japan. Am J Nephrol. (2015) 41:138-46. doi: $10.1159 / 000381106$

131. Chhana A, Lee G, Dalbeth N. Factors influencing the crystallization of monosodium urate: a systematic literature review. BMC Musculoskelet Disord. (2015) 16:296. doi: 10.1186/s12891-015-0762-4

132. Campion EW, Glynn RJ, DeLabry LO. Asymptomatic hyperuricemia. Risks and consequences in the Normative Aging Study. Am J Med. (1987) 82:4216. doi: 10.1016/0002-9343(87)90441-4

133. Keenan RT. Limitations of the current standards of care for treating gout and crystal deposition in the primary care setting: a review. Clin Ther (2017) 39:430-41. doi: 10.1016/j.clinthera.2016.12.011

134. Li Q, Li X, Kwong JS, Chen H, Sun X, Tian H, et al. Diagnosis and treatment for hyperuricaemia and gout: a protocol for a systematic review of clinical practice guidelines and consensus statements. BMJ Open (2017) 7:e014928. doi: 10.1136/bmjopen-2016-014928

135. Khanna D, Fitzgerald JD, Khanna PP, Bae S, Singh MK, Neogi T, et al. 2012 American College of Rheumatology guidelines for management of gout. Part 1: systematic nonpharmacologic and pharmacologic therapeutic approaches to hyperuricemia. Arthritis Care Res. (2012a) 64:1431-46. doi: $10.1002 /$ acr.21772

136. Khanna D, Khanna PP, Fitzgerald JD, Singh MK, Bae S, Neogi T, et al. 2012 American College of Rheumatology guidelines for management of gout. Part 2: therapy and antiinflammatory prophylaxis of acute gouty arthritis. Arthritis Care Res. (2012b) 64:1447-61. doi: 10.1002/acr.21773

137. Yamanaka H. Essence of the revised guideline for the management of hyperuricemia and gout. Japan Med Assoc J. (2012) 55:324-9.

138. Pascual E, Andres M, Vela P. Gout treatment: should we aim for rapid crystal dissolution? Ann Rheum Dis. (2013a) 72:635-7. doi: 10.1136/annrheumdis-2012-202594

139. Schlesinger N. Difficult-to-treat gouty arthritis:a disease warranting better management.Drugs (2011) 71:1413-39. doi: 10.2165/11592290-00000000000000

140. Harrold LR, Andrade SE, Briesacher BA, Raebel MA, Fouayzi H, Yood RA, et al. Adherence with urate-lowering therapies for the treatment of gout. Arthritis Res Ther. (2009) 11:R46. doi: 10.1186/ar2659

141. Silva L, Miguel ED, Peiteado D, Villalba A, Mola M, Pinto J, et al. Compliance in gout patients. Acta Reumatol Port. (2010) 35:466-74.

142. Feng X, Li Y, Gao W. Prophylaxis on gout flares after the initiation of urate-lowering therapy: a retrospective research. Int J Clin Exp Med. (2015) 8:21460-5.

143. Yu J, Qiu Q, Liang L, Yang X, Xu H Prophylaxis of acute flares when initiating febuxostat for chronic gouty arthritis in a real-world clinical setting. Mod Rheumatol. (2017) 28:339-44. doi: 10.1080/14397595.2017.1318467

144. McQueen FM, Chhana A, Dalbeth N. Mechanisms of joint damage in gout: evidence from cellular and imaging studies. Nat Rev Rheumatol. (2012) 8:173-81. doi: 10.1038/nrrheum.2011.207

145. Pascual E, Batlle-Gualda E, Martinez A, Rosas J, Vela P. Synovial fluid analysis for diagnosis of intercritical gout. Ann Intern Med. (1999) 131:7569. doi: 10.7326/0003-4819-131-10-199911160-00007

146. Perez-Ruiz F, Calabozo M, Pijoan JI, Herrero-Beites AM, Ruibal A. Effect of urate-lowering therapy on the velocity of size reduction of tophi in chronic gout. Arthritis Rheum. (2002) 47:356-60. doi: 10.1002/art.10511

147. Pascual E, Martinez A, Ordonez S. Gout: the mechanism of urate crystal nucleation and growth. A hypothesis based in facts. Joint Bone Spine (2013b) 80:1-4. doi: 10.1016/j.jbspin.2012.08.012

148. Ngo TC, Assimos DG. Uric Acid nephrolithiasis: recent progress and future directions. Rev Urol. (2007) 9:17-27.

149. Spivacow FR, Del Valle EE, Lores E, Rey PG. Kidney stones: composition, frequency and relation to metabolic diagnosis. Medicina (2016) 76:343-8.

150. Mandel NS, Mandel IC, Kolbach-Mandel AM. Accurate stone analysis: the impact on disease diagnosis and treatment.Urolithiasis (2017) 45:3-9. doi: 10.1007/s00240-016-0943-0

151. Richette P, Perez-Ruiz F, Doherty M, Jansen TL, Nuki G, Pascual $\mathrm{E}$, et al. Improving cardiovascular and renal outcomes in gout: what should we target? Nat Rev Rheumatol. (2014) 10:654-61. doi: $10.1038 /$ nrrheum.2014.124
152. Essex MN, Hopps M, Bienen EJ, Udall M, Mardekian J, Makinson GT. Evaluation of the relationship between serum uric acid levels and cardiovascular events in patients with gout: a retrospective analysis using electronic medical record data. J Clin Rheumatol. (2017) 23:160-6. doi: 10.1097/RHU.0000000000000496

153. Kuwabara M, Niwa K, Hisatome I, Nakagawa T, Roncal-Jimenez CA, Andres-Hernando A, et al. Asymptomatic hyperuricemia without comorbidities predicts cardiometabolic diseases: fiveyear japanese cohort study. Hypertension (2017b) 69:1036-44. doi: 10.1161/HYPERTENSIONAHA.116.08998

154. Kuwabara M, Niwa K, Nishihara S, Nishi Y, Takahashi O, Kario K, et al. Hyperuricemia is an independent competing risk factor for atrial fibrillation. Int J Cardiol. (2017c) 231:137-42. doi: 10.1016/j.ijcard.2016.11.268

155. Kuwabara M, Bjornstad P, Hisatome I, Niwa K, Roncal-Jimenez CA, AndresHernando A, et al. Elevated serum uric acid level predicts rapid decline in kidney function. Am J Nephrol. (2017a) 45:330-7. doi: 10.1159/000464260

156. Bardin T, Richette P. Impact of comorbidities on gout and hyperuricaemia: an update on prevalence and treatment options. BMC Med. (2017) 15:123. doi: 10.1186/s12916-017-0890-9

157. Bove M, Cicero AF, Veronesi M, Borghi C. An evidence-based review on urate-lowering treatments: implications for optimal treatment of chronic hyperuricemia. Vasc Health Risk Manag. (2017) 13:23-8. doi: 10.2147/VHRM.S115080

158. Kleber ME, Delgado G, Grammer TB, Silbernagel G, Huang J, Kramer BK, et al. Uric acid and cardiovascular events: a mendelian randomization study. J Am Soc Nephrol. (2015) 26:2831-8. doi: 10.1681/ASN.2014070660

159. Parsa A, Brown E, Weir MR, Fink JC, Shuldiner AR, Mitchell BD, et al. Genotype-based changes in serum uric acid affect blood pressure. Kidney Int. (2012) 81:502-7. doi: 10.1038/ki.2011.414

160. White J, Sofat R, Hemani G, Shah T, Engmann J, Dale C, et al. Plasma urate concentration and risk of coronary heart disease: a Mendelian randomisation analysis. Lancet Diabetes Endocrinol. (2016) 4:327-36. doi: 10.1016/S2213-8587(15)00386-1

161. Pfister R, Barnes D, Luben R, Forouhi NG, Bochud M, Khaw KT, et al. No evidence for a causal link between uric acid and type 2 diabetes: a Mendelian randomisation approach. Diabetologia (2011) 54:2561-9. doi: 10.1007/s00125-011-2235-0

162. Sluijs I, Holmes MV, van der Schouw YT, Beulens JW, Asselbergs FW, Huerta $\mathrm{JM}$, et al. A mendelian randomization study of circulating uric acid and type 2 diabetes. Diabetes (2015) 64:3028-36. doi: 10.2337/db14-0742

163. Rasheed H, Hughes K, Flynn TJ, Merriman TR. Mendelian randomization provides no evidence for a causal role of serum urate in increasing serum triglyceride levels. Circ Cardiovasc Genet. (2014) 7:830-7. doi: 10.1161/CIRCGENETICS.114.000556

164. Lyngdoh T, Vuistiner P, Marques-Vidal P, Rousson V, Waeber G, Vollenweider P, et al. Serum uric acid and adiposity: deciphering causality using a bidirectional Mendelian randomization approach. PLoS ONE (2012) 7:e39321. doi: 10.1371/journal.pone.0039321

165. Li X, Meng X, Timofeeva M, Tzoulaki I, Tsilidis KK, Ioannidis JP, et al. Serum uric acid levels and multiple health outcomes: umbrella review of evidence from observational studies, randomised controlled trials, and Mendelian randomisation studies. BMJ (2017) 357:j2376. doi: 10.1136/bmj.j2376

166. Robinson PC, Choi HK, Do R, Merriman TR. Insight into rheumatological cause and effect through the use of Mendelian randomization. Nat Rev Rheumatol. (2016) 12:486-96. doi: 10.1038/nrrheum.2016.102

167. Bose B, Badve SV, Hiremath SS, Boudville N, Brown FG, Cass A, et al. Effects of uric acid-lowering therapy on renal outcomes: a systematic review and meta-analysis. Nephrol Dial Transplant. (2014) 29:406-13. doi: $10.1093 / \mathrm{ndt} / \mathrm{gft} 378$

168. Mallat SG, Al Kattar S, Tanios BY, Jurjus A. Hyperuricemia, hypertension, and chronic kidney disease: an emerging association. Curr Hypertens Rep. (2016) 18:74. doi: 10.1007/s11906-016-0684-z

169. Borghi C. The role of uric acid in the development of cardiovascular disease. Curr Med Res Opin. (2015) 31 (Suppl. 2):1-2. doi: 10.1185/03007995.2015. 1087985

170. Borghi C, Rosei EA, Bardin T, Dawson J, Dominiczak A, Kielstein JT, et al. Serum uric acid and the risk of cardiovascular and renal disease. J Hypertens. (2015) 33:1729-41; discussion 1741. doi: 10.1097/HJH.0000000000000701 
171. Mancia G, Grassi G, Borghi C. Hyperuricemia, urate deposition and the association with hypertension. Curr Med Res Opin. (2015) 31 (Suppl. 2):1519. doi: 10.1185/03007995.2015.1087981

172. Kawasoe S, Kubozono T, Yoshifuku S, Ojima S, Oketani N, Miyata $\mathrm{M}$, et al. Uric acid level and prevalence of atrial fibrillation in a Japanese general population of 285,882. Circ J. (2016) 80:2453-9. doi: 10.1253/circj.CJ-16-0766

173. Alper AB Jr., Chen W, Yau L, Srinivasan SR, Berenson GS, Hamm LL. Childhood uric acid predicts adult blood pressure: the Bogalusa Heart Study.Hypertension (2005) 45:34-8. doi: 10.1161/01.HYP.0000150783.79172.bb

174. Feig DI. The role of uric acid in the pathogenesis of hypertension in the young. J Clin Hypertens. (2012) 14:346-52. doi: 10.1111/j.1751-7176.2012.00662.x

175. Loeffler LF, Navas-Acien A, Brady TM, Miller ER III, Fadrowski JJ. Uric acid level and elevated blood pressure in US adolescents: National Health and Nutrition Examination Survey, 1999-2006.Hypertension (2012) 59:811-7. doi: 10.1161/HYPERTENSIONAHA.111.183244

176. Soletsky B, Feig D.I. Uric acid reduction rectifies prehypertension in obese adolescents. Hypertension (2012) 60:1148-56. doi: 10.1161/HYPERTENSIONAHA.112.196980

177. Mazza A, Lenti S, Schiavon L, Monte AD, Townsend DM, Ramazzina E, et al. Asymptomatic hyperuricemia is a strong risk factor for resistant hypertension in elderly subjects from general population. Biomed Pharmacother. (2017) 86:590-4. doi: 10.1016/j.biopha.2016.11.104

178. Puddu P, Puddu GM, Cravero E, Vizioli L, Muscari A. Relationships among hyperuricemia, endothelial dysfunction and cardiovascular disease: molecular mechanisms and clinical implications. J Cardiol. (2012) 59:23542. doi: 10.1016/j.jjcc.2012.01.013

179. Schuchardt M, Herrmann J, Tolle M, van der Giet M. Xanthine oxidase and its role as target in cardiovascular disease: cardiovascular protection by enzyme inhibition? Curr Pharm Des. (2017) 23:3391-404. doi: 10.2174/1381612823666170417130115

180. Scheepers LE, Wei FF, Stolarz-Skrzypek K, Malyutina S, Tikhonoff V, Thijs $\mathrm{L}$, et al. Xanthine oxidase gene variants and their association with blood pressure and incident hypertension: a population study. J Hypertens. (2016) 34:2147-54. doi: 10.1097/HJH.0000000000001077

181. Tani S, Nagao K, Hirayama A. Effect of febuxostat, a xanthine oxidase inhibitor, on cardiovascular risk in hyperuricemic patients with hypertension: a prospective, open-label, pilot study. Clin Drug Investig. (2015) 35:823-31. doi: 10.1007/s40261-015-0349-8

182. Kojima S, Kojima S, Hifumi A, Soejima H, Ogawa H. Therapeutic strategy for efficient reduction of serum uric acid levels with allopurinol versus benzbromarone in hyperuricemic patients with essential hypertension - A randomized crossover study (terao study). Int J Cardiol. (2016) 224:437-9. doi: 10.1016/j.ijcard.2016.09.073

183. Mackenzie IS, Ford I, Walker A, Hawkey C, Begg A, Avery A, et al. Multicentre, prospective, randomised, open-label, blinded end point trial of the efficacy of allopurinol therapy in improving cardiovascular outcomes in patients with ischaemic heart disease: protocol of the ALL-HEART study. BMJ Open (2016) 6:e013774. doi: 10.1136/bmjopen-2016-013774

184. Kojima S, Matsui K, Ogawa $H$, Jinnouchi $H$, Hiramitsu S, Hayashi $T$, et al. Rationale, design, baseline characteristics of a study to evaluate the effect of febuxostat in preventing cerebral, cardiovascular, and renal events in patients with hyperuricemia. J Cardiol. (2017) 69:169-75. doi: 10.1016/j.jjcc.2016.02.015

185. Larsen KS, Pottegard A, Lindegaard H, Hallas J. Is urate crystal precipitation a predictor of cardiovascular risk in hyperuricemic patients? A Danish cohort study. Arthritis Res Ther. (2015) 17:304. doi: 10.1186/s13075-015-0 $822-\mathrm{z}$

186. Wei L, Mackenzie IS, Chen Y, Struthers AD, MacDonald TM. Impact of allopurinol use on urate concentration and cardiovascular outcome. Br J Clin Pharmacol. (2011) 71:600-7. doi: 10.1111/j.1365-2125.2010.03 887.x

187. Cottrell E, Crabtree V, Edwards JJ, Roddy E. Improvement in the management of gout is vital and overdue: an audit from a UK primary care medical practice. BMC Fam Pract. (2013) 14:170. doi: 10.1186/1471-2296-14-170
188. Hatoum H, Khanna D, Lin SJ, Akhras KS, Shiozawa A, Khanna P. Achieving serum urate goal: a comparative effectiveness study between allopurinol and febuxostat. Postgrad Med. (2014) 126:65-75. doi: 10.3810/pgm.2014.03.2741

189. Keenan T, Zhao W, Rasheed A, Ho WK, Malik R, Felix JF, et al. Causal assessment of serum urate levels in cardiometabolic diseases through a mendelian randomization study. J Am Coll Cardiol. (2016) 67:407-16. doi: 10.1016/j.jacc.2015.10.086

190. Greenberg KI, McAdams-DeMarco MA, Kottgen A, Appel LJ, Coresh J, Grams ME. Plasma urate and risk of a hospital stay with AKI: the atherosclerosis risk in communities study. Clin J Am Soc Nephrol. (2015) 10:776-83. doi: 10.2215/CJN.05870614

191. Xu X, Hu J, Song N, Chen R, Zhang T, Ding X. Hyperuricemia increases the risk of acute kidney injury: a systematic review and meta-analysis. $B M C$ Nephrol. (2017) 18:27. doi: 10.1186/s12882-016-0433-1

192. Ejaz AA, Mu W, Kang DH, Roncal C, Sautin YY, Henderson G, et al. Could uric acid have a role in acute renal failure? Clin J Am Soc Nephrol. (2007) 2:16-21. doi: 10.2215/CJN.00350106

193. Shimada M, Dass B, Ejaz AA. Paradigm shift in the role of uric acid in acute kidney injury. Semin Nephrol. (2011) 31:453-8. doi: 10.1016/j.semnephrol.2011.08.010

194. Perez-Ruiz F, Calabozo M, Herrero-Beites AM, Garcia-Erauskin G, Pijoan JI. Improvement of renal function in patients with chronic gout after proper control of hyperuricemia and gouty bouts.Nephron (2000) 86:287-91. doi: $10.1159 / 000045783$

195. Siu YP, Leung KT, Tong MK, Kwan TH. Use of allopurinol in slowing the progression of renal disease through its ability to lower serum uric acid level. Am J Kidney Dis. (2006) 47:51-9. doi: 10.1053/j.ajkd.2005. 10.006

196. Khan M, Khan RA, Islam F, Laghari J, Jamali SN. To study the efficacy of Losartan on urinary uric acid excretion in Thiazide induced hyperuricemic and hypertensive patients. Pak J Pharm Sci. (2011) 24:583-7.

197. Maahs DM, Caramori L, Cherney DZ, Galecki AT, Gao C, Jalal D, et al. Uric acid lowering to prevent kidney function loss in diabetes: the preventing early renal function loss (PERL) allopurinol study. Curr Diab Rep. (2013) 13:550-9. doi: 10.1007/s11892-013-0381-0

198. Kanji T, Gandhi M, Clase CM, Yang R. Urate lowering therapy to improve renal outcomes in patients with chronic kidney disease: systematic review and meta-analysis. BMC Nephrol. (2015) 16:58. doi: 10.1186/s12882-015-0047-z

199. Chiba T, Matsuo H, Kawamura Y, Nagamori S, Nishiyama T, Wei $\mathrm{L}$, et al. NPT1/SLC17A1 is a renal urate exporter in humans and its common gain-of-function variant decreases the risk of renal underexcretion gout. Arthritis Rheumatol. (2015) 67:281-7. doi: 10.1002/ art.38884

200. Sircar D, Chatterjee S, Waikhom R, Golay V, Raychaudhury A, Chatterjee S, et al. Efficacy of Febuxostat for Slowing the GFR Decline in Patients With C. K. D., and Asymptomatic Hyperuricemia: A 6-Month, Double-Blind, Randomized, Placebo-Controlled Trial. Am J Kidney Dis. (2015) 66:945-50. doi: 10.1053/j.ajkd.2015.05.017

201. Hughes K, Flynn T, de Zoysa J, Dalbeth N, Merriman TR. Mendelian randomization analysis associates increased serum urate, due to genetic variation in uric acid transporters, with improved renal function. Kidney Int. (2014) 85:344-51. doi: 10.1038/ki.2013.353

202. Goldfarb DS, MacDonald PA, Hunt B, Gunawardhana L. Febuxostat in gout: serum urate response in uric acid overproducers and underexcretors. J Rheumatol. (2011) 38:1385-9. doi: 10.3899/jrheum.101156

203. Gillen DL, Worcester EM, Coe FL. Decreased renal function among adults with a history of nephrolithiasis: a study of NHANES III. Kidney Int. (2005) 67:685-90. doi: 10.1111/j.1523-1755.2005.67128.x

204. Madero M, Sarnak MJ, Wang X, Greene T, Beck GJ, Kusek JW, et al. Uric acid and long-term outcomes in CKD. Am J Kidney Dis. (2009) 53:796-803. doi: 10.1053/j.ajkd.2008.12.021

205. Chou YC, Kuan JC, Yang T, Chou WY, Hsieh PC, Bai CH, et al. Elevated uric acid level as a significant predictor of chronic kidney disease: a cohort study with repeated measurements. J Nephrol. (2015) 28:457-62. doi: 10.1007/s40620-014-0158-9

206. Rodenbach KE, Schneider MF, Furth SL, Moxey-Mims MM, Mitsnefes MM, Weaver DJ, et al. Hyperuricemia and Progression of CKD in Children and 
Adolescents: The Chronic Kidney Disease in Children (CKiD) Cohort Study. Am J Kidney Dis. (2015) 66:984-92. doi: 10.1053/j.ajkd.2015.06.015

207. Murphy D, McCulloch CE, Lin F, Banerjee T, Bragg-Gresham JL, Eberhardt MS, et al. Trends in prevalence of chronic kidney disease in the United States. Ann Intern Med. (2016) 165:473-81. doi: 10.7326/M16-0273

208. Sarathy H, Henriquez G, Abramowitz MK, Kramer H, Rosas SE, Johns $\mathrm{T}$, et al. Abdominal obesity, race and chronic kidney disease in young adults: results from NHANES 1999-2010. PLoS ONE (2016) 11:e0153588. doi: 10.1371/journal.pone. 0153588

209. Nashar K, Fried LF. Hyperuricemia and the progression of chronic kidney disease: is uric acid a marker or an independent risk factor? Adv Chronic Kidney Dis. (2012) 19:386-91. doi: 10.1053/j.ackd.2012.05.004

210. Bhole V, Choi JW, Kim SW, de Vera M, Choi H. Serum uric acid levels and the risk of type 2 diabetes: a prospective study. Am J Med. (2010) 123:957-61. doi: 10.1016/j.amjmed.2010.03.027

211. Araki S, Nishio $Y$, Araki A, Umegaki H, Sakurai T, Iimuro S, et al. Factors associated with progression of diabetic nephropathy in Japanese elderly patients with type 2 diabetes: sub-analysis of the Japanese Elderly Diabetes Intervention Trial. Geriatr Gerontol Int. (2012) 12 (Suppl. 1):12733. doi: 10.1111/j.1447-0594.2011.00820.x

212. Xu Y, Zhu J, Gao L, Liu Y, Shen J, Shen C, et al. Hyperuricemia as an independent predictor of vascular complications and mortality in type 2 diabetes patients: a meta-analysis. PLoS ONE (2013) 8:e78206. doi: 10.1371/journal.pone.0078206

213. Yu S, Chen $\mathrm{Y}$, Hou X, Xu D, Che $\mathrm{K}, \mathrm{Li} \mathrm{C}$, et al. Serum uric acid levels and diabetic peripheral neuropathy in type 2 diabetes: a systematic review and meta-analysis. Mol Neurobiol. (2016) 53:1045-51. doi: $10.1007 / \mathrm{s} 12035-014-9075-0$

214. Liu P, Chen Y, Wang B, Zhang F, Wang D, Wang Y. Allopurinol treatment improves renal function in patients with type 2 diabetes and asymptomatic hyperuricemia: 3-year randomized parallel-controlled study. Clin Endocrinol. (2015) 83:475-82. doi: 10.1111/cen.12673

215. Takir M, Kostek O, Ozkok A, Elcioglu OC, Bakan A, Erek A, et al. Lowering uric acid with allopurinol improves insulin resistance and systemic inflammation in asymptomatic hyperuricemia. J Investig Med. (2015) 63:924-9. doi: 10.1097/JIM.0000000000000242

216. Ito $H$, Antoku $S$, Abe $M$, Omoto $T$, Shinozaki $M$, Nishio $S$, et al. Comparison of the renoprotective effect of febuxostat for the treatment of hyperuricemia between patients with and without type 2 diabetes mellitus: a retrospective observational study. Intern Med. (2016) 55:3247-56. doi: 10.2169/internalmedicine.55.6791

217. Johnson RJ, Merriman T, Lanaspa MA. Causal or noncausal relationship of uric acid with diabetes.Diabetes (2015) 64:2720-2. doi: 10.2337/db15-0532

218. Musso G, Gambino R, Cassader M, Pagano G. A novel approach to control hyperglycemia in type 2 diabetes: sodium glucose cotransport (SGLT) inhibitors: systematic review and meta-analysis of randomized trials. Ann Med. (2012) 44:375-93. doi: 10.3109/07853890.2011. 560181

219. Caulfield MJ, Munroe PB, O’Neill D, Witkowska K, Charchar FJ, Doblado $\mathrm{M}$, et al. SLC2A9 is a high-capacity urate transporter in humans. PLoS Med. (2008) 5:e197. doi: 10.1371/journal.pmed.0050197

220. Aung T, Myung G, FitzGerald JD. Treatment approaches and adherence to urate-lowering therapy for patients with gout. Patient PreferAdherence (2017) 11:795-800. doi: 10.2147/PPA.S97927

221. Qu LH, Jiang H, Chen JH. Effect of uric acid-lowering therapy on blood pressure: systematic review and meta-analysis. Ann Med. (2017) 49:142-56. doi: 10.1080/07853890.2016.1243803

222. Watts RW. Uric acid production with particular reference to the role of xanthine oxidase and its inhibition. Proc R Soc Med. (1966) 59:287-92.

223. Becker MA, Schumacher HR Jr., Wortmann RL, MacDonald PA, Eustace D, Palo WA, et al. Febuxostat compared with allopurinol in patients with hyperuricemia and gout. $N$ Engl J Med. (2005) 353:2450-61. doi: 10.1056/NEJMoa050373

224. Jennings C G., Mackenzie I S., Flynn R, Ford I, Nuki G, De Caterina R, et al. Up-titration of allopurinol in patients with gout. Semin Arthritis Rheum. (2014) 44:25-30. doi: 10.1016/j.semarthrit.2014.01.004

225. Jordan KM, Cameron JS, Snaith M, Zhang W, Doherty M, Seckl J, et al. British Society for Rheumatology and British Health Professionals in
Rheumatology guideline for the management of gout. Rheumatology (2007) 46:1372-4. doi: 10.1093/rheumatology/kem056a

226. Mikuls TR, Farrar JT, Bilker WB, Fernandes S, Saag KG. Suboptimal physician adherence to quality indicators for the management of gout and asymptomatic hyperuricaemia: results from the UK General Practice Research Database (GPRD). Rheumatology (2005) 44:1038-42. doi: 10.1093/rheumatology/keh679

227. Shahid H, Singh JA. Investigational drugs for hyperuricemia. Expert Opin Invest Drugs (2015) 24:1013-30. doi: 10.1517/13543784.2015.1051617

228. Halevy S, Ghislain P-D., Mockenhaupt M, Fagot J-P., Bouwes Bavinck Jan N, Sidoroff A, et al. Allopurinol is the most common cause of Stevens-Johnson syndrome and toxic epidermal necrolysis in Europe and Israel. J Am Acad Dermatol. (2008) 58:25-32. doi: 10.1016/j.jaad.2007.08.036

229. Stamp LK, Day RO, Yun J. Allopurinol hypersensitivity: investigating the cause and minimizing the risk. Nat Rev Rheumatol. (2016) 12:235-42. doi: 10.1038/nrrheum.2015.132

230. Chao J, Terkeltaub R. A critical reappraisal of allopurinol dosing, safety, and efficacy for hyperuricemia in gout. Curr Rheumatol Rep. (2009) 11:135-40. doi: 10.1007/s11926-009-0019-z

231. Jick H, Porter JB. Potentiation of ampicillin skin reactions by allopurinol or hyperuricemia. J Clin Pharmacol. (1981) 21:456-8. doi: 10.1002/j.1552-4604.1981.tb01749.x

232. Singh JA, Akhras KS, Shiozawa A. Comparative effectiveness of urate lowering with febuxostat versus allopurinol in gout: analyses from large U.S. managed care cohort. Arthritis Res Ther. (2015) 17:120. doi: 10.1186/s13075-015-0624-3

233. Bridgeman MB, Chavez B. Febuxostat for the treatment of gout. Expert Opin Pharmacother. (2015) 16:395-8. doi: 10.1517/14656566.2015.9 85588

234. Chohan S. Safety and efficacy of febuxostat treatment in subjects with gout and severe allopurinol adverse reactions. J Rheumatol. (2011) 38:1957-9. doi: 10.3899/jrheum.110092

235. Miyata H, Takada T, Toyoda Y, Matsuo H, Ichida K, Suzuki H. Identification of febuxostat as a new strong ABCG2 inhibitor: potential applications and risks in clinical situations. Front Pharmacol. (2016) 7:518. doi: $10.3389 /$ fphar.2016.00518

236. Schumacher HR Jr., Becker MA, Wortmann RL, Macdonald PA, Hunt B, Streit J, et al. Effects of febuxostat versus allopurinol and placebo in reducing serum urate in subjects with hyperuricemia and gout: a 28 -week, phase III, randomized, double-blind, parallel-group trial. Arthritis Rheum. (2008) 59:1540-8. doi: 10.1002/art.24209

237. Paschou E, Gavriilaki E, Kalaitzoglou A, Papaioannou G, Tsompanakou A, Sabanis N. "Febuxostat hypersensitivity: another cause of DRESS syndrome in chronic kidney disease?”. Eur Ann Allergy Clin Immunol. (2016) 48:251-5.

238. White WB, Saag KG, Becker MA, Borer JS, Gorelick PB, Whelton A, et al. Cardiovascular Safety of Febuxostat or Allopurinol in Patients with Gout. N Engl J Med. (2018) 378:1200-10. doi: 10.1056/NEJMoal7 10895

239. Beard SM, von Scheele BG, Nuki G, Pearson IV. Cost-effectiveness of febuxostat in chronic gout. Eur J Health Econ. (2014) 15:453-63. doi: 10.1007/s10198-014-0617-1

240. Gandhi PK, Gentry WM, Ma Q, Bottorff MB. Cost-effectiveness analysis of allopurinol versus febuxostat in chronic gout patients: a U.S. payer perspective. J Manag Care Spec Pharm. (2015) 21:165-75. doi: 10.18553/jmcp.2015.21.2.165

241. Hosoya T, Ogawa Y, Hashimoto H, Ohashi T, Sakamoto R. Comparison of topiroxostat and allopurinol in Japanese hyperuricemic patients with or without gout: aphase 3 , multicentre, randomized, double-blind, doubledummy, active-controlled, parallel-group study. J Clin Pharm Ther. (2016) 41:290-7. doi: 10.1111/jcpt.12391

242. Horino T, Hatakeyama Y, Ichii O, Matsumoto T, Shimamura Y, Inoue K, et al. Effects of topiroxostat in hyperuricemic patients with chronic kidney disease. Clin Exp Nephrol. (2017) 22:337-45. doi: 10.1007/s10157-0171452-3

243. Sato T, Ashizawa N, Matsumoto K, Iwanaga T, Nakamura H, Inoue T, et al. Discovery of 3-(3-cyano-4-pyridyl)-5-(4-pyridyl)-1,2,4-triazole, FYX-051 - a xanthine oxidoreductase inhibitor for the treatment of hyperuricemia Bioorg Med Chem Lett. (2009) 19:6225-9. doi: 10.1016/j.bmcl.2009.08.091 
244. Matsumoto K, Okamoto K, Ashizawa N, Nishino T. FYX-051: a novel and potent hybrid-type inhibitor of xanthine oxidoreductase. J Pharmacol Exp Ther. (2011) 336:95-103. doi: 10.1124/jpet.110.174540

245. Pittman JR., Bross MH. Diagnosis and management of gout. Am Fam Physician (1999) 59:1799-806.

246. Perez-Ruiz F, Hernandez-Baldizon S, Herrero-Beites AM, Gonzalez-Gay MA. Risk factors associated with renal lithiasis during uricosuric treatment of hyperuricemia in patients with gout. Arthritis Care Res. (2010) 62:1299-305. doi: 10.1002/acr.20221

247. Hamada T, Ichida K, Hosoyamada M, Mizuta E, Yanagihara K, Sonoyama $\mathrm{K}$, et al. Uricosuric action of losartan via the inhibition of urate transporter 1 (URAT 1) in hypertensive patients. Am J Hypertens. (2008) 21:1157-62. doi: 10.1038/ajh.2008.245

248. Lee M-HH, Graham GG, Williams KM, Day RO. A benefit-risk assessment of benzbromarone in the treatment of gout: was its withdrawal from the market in the best interest of patients? Drug Saf. (2008) 31:643-65. doi: 10.2165/00002018-200831080-00002

249. Robbins N, Koch SE, Tranter M, Rubinstein J. The history and future of probenecid. Cardiovasc Toxicol. (2012) 12:1-9. doi: 10.1007/s12012-011-9145-8

250. Pui K, Gow PJ, Dalbeth N. Efficacy and tolerability of probenecid as uratelowering therapy in gout; clinical experience in high-prevalence population. J Rheumatol. (2013) 40:872-6. doi: 10.3899/jrheum.121301

251. Reinders MK, van Roon EN, Jansen TLTA, Delsing J, Griep EN, Hoekstra M, et al. Efficacy and tolerability of urate-lowering drugs in gout: a randomised controlled trial of benzbromarone versus probenecid after failure of allopurinol. Ann Rheum Dis. (2009b) 68:51-6. doi: 10.1136/ard.2007. 083071

252. Reinders MK, Haagsma C, Jansen TLTA, van Roon EN, Delsing J, van de Laar MAFJ, et al. A randomised controlled trial on the efficacy and tolerability with dose escalation of allopurinol 300-600 mg/day versus benzbromarone 100-200 mg/day in patients with gout. Ann Rheum Dis. (2009a) 68:892-7. doi: 10.1136/ard.2008.091462

253. Hisatome I, Tanaka Y, Kotake H, Kosaka H, Hirata N, Fujimoto Y, et al. Renal hypouricemia due to enhanced tubular secretion of urate associated with urolithiasis: successful treatment of urolithiasis by alkalization of urine $\mathrm{K}+, \mathrm{Na}(+)$-citrate. Nephron (1993) 65:578-82. doi: 10.1159/000187567

254. Shen Z, Yeh LT, Wallach K, Zhu N, Kerr B, Gillen M. In Vitro and In Vivo interaction studies between lesinurad, a selective urate reabsorption inhibitor, and major liver or kidney transporters. Clin Drug Investig. (2016) 36:443-52. doi: 10.1007/s40261-016-0386-y

255. Gillen M, Yang C, Wilson D, Valdez S, Lee C, Kerr B, et al. Evaluation of pharmacokinetic interactions between lesinurad, a new selective urate reabsorption inhibitor, and CYP enzyme substrates sildenafil, amlodipine, tolbutamide, and repaglinide. Clin Pharmacol Drug Dev. (2017) 6:363-76. doi: $10.1002 /$ cpdd. 324

256. Shen Z, Tieu K, Wilson D, Bucci G, Gillen M, Lee C, et al. Evaluation of pharmacokinetic interactions between lesinurad, a new selective urate reabsorption inhibitor, and commonly used drugs for gout treatment. Clin Pharmacol Drug Dev. (2017) 6:377-87. doi: 10.1002/cpdd.323

257. Fleischmann R, Kerr B, Yeh L-T, Suster M, Shen Z, Polvent E, et al. Pharmacodynamic, pharmacokinetic and tolerability evaluation of concomitant administration of lesinurad and febuxostat in gout patients with hyperuricaemia. Rheumatology (2014) 53:2167-74. doi: 10.1093/rheumatology/ket487

258. Perez-Ruiz F, Sundy JS, Miner JN, Cravets M, Storgard C, Group RS. Lesinurad in combination with allopurinol: results of a phase 2, randomised, double-blind study in patients with gout with an inadequate response to allopurinol. Ann Rheum Dis. (2016) 75:1074-80. doi: 10.1136/annrheumdis-2015-207919

259. Bardin T, Keenan RT, Khanna PP, Kopicko J, Fung M, Bhakta N, et al. Lesinurad in combination with allopurinol: a randomised, doubleblind, placebo-controlled study in patients with gout with inadequate response to standard of care (the multinational CLEAR 2 study). Ann Rheum Dis. (2017) 76:811-20. doi: 10.1136/annrheumdis-2016209213

260. Dalbeth N, Jones G, Terkeltaub R, Khanna D, Kopicko J, Bhakta N, et al. Lesinurad, a selective uric acid reabsorption inhibitor, in combination with febuxostat in patients with tophaceous gout: findings of a phase III clinical trial. Arthritis Rheumatol. (2017) 69:1903-1913. doi: 10.1002/art. 40159

261. Saag KG, Fitz-Patrick D, Kopicko J, Fung M, Bhakta N, Adler S, et al. Lesinurad combined with allopurinol: a randomized, double-blind, placebocontrolled study in gout patients with an inadequate response to standard-ofcare allopurinol (a US-Based Study). Arthritis Rheumatol. (2017) 69:203-12. doi: 10.1002/art.39840

262. Tausche AK, Alten R, Dalbeth N, Kopicko J, Fung M, Adler S, et al. Lesinurad monotherapy in gout patients intolerant to a xanthine oxidase inhibitor: a 6 month phase 3 clinical trial and extension study. Rheumatology (2017) 56:2170-8. doi: 10.1093/rheumatology/kex350

263. Hoy SM. Lesinurad: first global approval.Drugs (2016) 76:509-16. doi: 10.1007/s40265-016-0550-y

264. Deeks E.D. Lesinurad: a review in hyperuricaemia of gout. Drugs Aging (2017) 34:401-10. doi: 10.1007/s40266-017-0461-y

265. Robinson PC, Dalbeth N. Lesinurad for the treatment of hyperuricaemia in people with gout. Expert Opin Pharmacother. (2017) 18:1875-81. doi: 10.1080/14656566.2017.1401609

266. Sherman MR, Saifer MGP, Perez-Ruiz F. PEG-uricase in the management of treatment-resistant gout and hyperuricemia. Adv. Drug Delivery Rev. (2008) 60:59-68. doi: 10.1016/j.addr.2007.06.011

267. Sundy JS, Baraf HSB, Yood RA, Edwards NL, Gutierrez-Urena SR, Treadwell EL, et al. Efficacy and tolerability of pegloticase for the treatment of chronic gout in patients refractory to conventional treatment. Two randomized controlled trials. J Am Med Assoc. (2011) 306:711-70. doi: 10.1001/jama.2011.1169

268. Taniguchi T, Ashizawa N, Matsumoto K, Iwanaga T. Enhancement of pharmacological effects of uricosuric agents by concomitant treatment with pyrazinamide in rats. Naunyn Schmiedebergs Arch Pharmacol. (2017) 390:253-60. doi: 10.1007/s00210-016-1324-5

269. Taniguchi T, Ashizawa N, Matsumoto K, Iwanaga T, Saitoh K. Uricosuric agents decrease the plasma urate level in rats by concomitant treatment with topiroxostat, a novel xanthine oxidoreductase inhibitor J Pharmacy Pharmacol. (2016) 68:76-83. doi: 10.1111/jphp.12490

270. Barranco C. Crystal arthritis Arhalofenate safely prevents gout flare. Nat Rev Rheumatol. (2016) 12:252. doi: 10.1038/nrrheum.2016.53

271. Choi, Y-J, Vanina L, Annette L, Vicena V, Abarca N, Rantz T, et al. Arhalofenate Is a Novel Dual-Acting Agent with Uricosuric and AntiInflammatory Properties. In: 2012 ACR/ARHP Annual Meeting. Hayward, CA (2012).

272. Dalbeth N, Lauterio TJ, Wolfe HR. Mechanism of action of colchicine in the treatment of gout. Clin Ther. (2014) 36:1465-79. doi: 10.1016/j.clinthera.2014.07.017

273. Shen Z, Gillen M, Miner JN, Bucci G, Wilson DM, Hall JW. Pharmacokinetics, pharmacodynamics, and tolerability of verinurad, a selective uric acid reabsorption inhibitor, in healthy adult male subjects. Drug Des Devel Ther. (2017) 11:2077-86. doi: 10.2147/DDDT. S140658

274. Moolenburgh JD, Reinders MK, Jansen TLTA. Rasburicase treatment in severe tophaceous gout: a novel therapeutic option. Clin Rheumatol. (2006) 25:749-52. doi: 10.1007/s10067-005-0043-y

275. Bluestone R, Campion D, Klinenberg JR. Halofenate. Its selection and trial as a primary uricosuric agent. Arthritis Rheum. (1975) 18 (Suppl. 6):859-62. doi: 10.1002/art.1780180732

276. Poiley J, Steinberg AS, Choi YJ, Davis CS, Martin RL, McWherter $\mathrm{CA}$, et al. A randomized, double-blind, active- and placebo-controlled efficacy and safety study of arhalofenate for reducing flare in patients with gout. Arthritis Rheumatol. (2016) 68:2027-34. doi: 10.1002/art. 39684

277. Steinberg AS, Vince BD, Choi YJ, Martin RL, McWherter CA, Boudes PF. The pharmacodynamics, pharmacokinetics, and safety of arhalofenate in combination with febuxostat when treating hyperuricemia associated with gout. J Rheumatol. (2017) 44:374-9. doi: 10.3899/jrheum. 161062

278. Diaz-Torne C, Perez-Herrero N, Perez-Ruiz F. New medications in development for the treatment of hyperuricemia of gout. Curr Opin Rheumatol. (2015) 27:164-9. doi: 10.1097/BOR.0000000000000146 
279. Fleischmann R, Winkle P, Miner J, Yan X, Hicks L, Valdez S, et al. AB0880 Pharmacodynamic effects and safety of verinurad (RDEA3170) in combination with allopurinol versus allopurinol alone in adults with gout: a phase 2a, open-label study. Ann Rheum Dis. (2017) 76 (Suppl. 2):1364. doi: 10.1136/annrheumdis-2017-eular.5429

280. Shiramoto M, Liu S, Shen Z, Hall J. THU0435 Pharmacodynamics, pharmacokinetics, and safety of verinurad (RDEA3170) in combination with febuxostat versus febuxostat alone and verinurad alone in japanese adults with gout or asymptomatic hyperuricemia: a phase $2 \mathrm{~A}$, open-label study. Ann Rheum Dis. (2017) 76 (Suppl. 2):371-2. doi: 10.1136/annrheumdis-2017-eula r.5391

281. Ahn SO, Ohtomo S, Kiyokawa J, Nakagawa T, Yamane M, Lee KJ, et al. Stronger uricosuric effects of the novel selective URAT1 inhibitor UR1102 lowered plasma urate in tufted capuchin monkeys to a greater extent than benzbromarone. J Pharmacol Exp Ther. (2016) 357:157-66. doi: 10.1124/jpet.115.231647

282. Yoon S, Shin D, Jang I-J, Yu K-S, Lee H. Pharmacokinetics, pharmacodynamics, and tolerability of LC350189, a novel xanthine oxidase inhibitor, in healthy subjects. Drug Des Dev Ther. (2015) 9:5033-49. doi: 10.2147/DDDT.S86884

283. Mandal AK, Mercado A, Foster A, Zandi-Nejad K, Mount DB. Uricosuric targets of tranilast. Pharmacol Res Perspect. (2017) 5:e00291. doi: $10.1002 /$ prp2.291

284. Dua P, Gurrell R, Kirby S, Sudworth M, Loudon PT. Acute kidney injury observed during phase 1 clinical trials of a novel xanthine oxidase/URAT1 dual inhibitor PF-06743649. Clin Rheumatol. (2016) 35:2045-51. doi: 10.1007/s10067-016-3273-2
285. Bantia S, Parker C, Upshaw R, Cunningham A, Kotian P, Kilpatrick $\mathrm{JM}$, et al. Potent orally bioavailable purine nucleoside phosphorylase inhibitor BCX-4208 induces apoptosis in B- and T-lymphocytes-a novel treatment approach for autoimmune diseases, organ transplantation and hematologic malignancies. Int Immunopharmacol. (2010) 10:784-90. doi: 10.1016/j.intimp.2010.04.009

286. Grunebaum E, Cohen A, Roifman CM. Recent advances in understanding and managing adenosine deaminase and purine nucleoside phosphorylase deficiencies. Curr Opin Allergy Clin Immunol. (2013) 13:630-8. doi: 10.1097/ACI.0000000000000006

287. Nguyen AD, Baysari MT, Kannangara DR, Tariq A, Lau AY, Westbrook JI, et al. Mobile applications to enhance self-management of gout. Int $J$ Med Inform. (2016) 94:67-74. doi: 10.1016/j.ijmedinf.2016. 06.021

Conflict of Interest Statement: CB is a paid employee of Astex Pharmaceuticals. PD, RG, and PL are paid employees of Pfizer Ltd. RS and AP are paid employees of AstraZeneca and inventors on patents for URAT1 inhibitors (not in active clinical development at the time of submission). CV is a paid employee of Genomics plc.

Copyright (c) 2018 Benn, Dua, Gurrell, Loudon, Pike, Storer and Vangjeli. This is an open-access article distributed under the terms of the Creative Commons Attribution License (CC BY). The use, distribution or reproduction in other forums is permitted, provided the original author(s) and the copyright owner are credited and that the original publication in this journal is cited, in accordance with accepted academic practice. No use, distribution or reproduction is permitted which does not comply with these terms. 